\title{
Antibacterial free-standing polysaccharide composite films inspired by the sea
}

\author{
A. Catarina Vale a,b Paulo Pereira ${ }^{\mathrm{a}, \mathrm{b}}$, A. Margarida Barbosa ${ }^{\mathrm{b}, \mathrm{c}}$, Egídio Torrado ${ }^{\mathrm{b}, \mathrm{c}}$, \\ João F. Mano ${ }^{\mathrm{a}, \mathrm{b}, 1}$, Natália M. Alves ${ }^{\mathrm{a}, \mathrm{b}, *}$

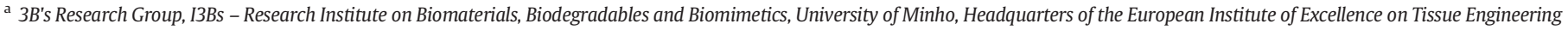 \\ and Regenerative Medicine, AvePark, 4805-017 Barco, Guimarães, Portugal \\ b ICVS/3B's PT Associate Laboratory, Guimarães, Portugal \\ c Life and Health Sciences Research Institute (ICVS), School of Health Sciences, University of Minho, Braga, Portugal
}

\section{A R T I C L E I N F O}

\section{Article history:}

Received 18 January 2019

Received in revised form 4 April 2019

Accepted 13 April 2019

Available online 16 April 2019

\section{Keywords:}

Natural-derived polysaccharides

Free-standings films

Silver containing bioglass nanoparticles

\begin{abstract}
A B S T R A C T
The adhesive capabilities of marine mussel proteins are well-known, exhibiting the ability to stick to different underwater substrates, either inorganic or organic. These unique adhesive properties are due to the high levels of amino acid, 3,4-dihydroxyphenyl-L-alanine (DOPA), which presents the reactive catechol group. Herein, novel antibacterial free-standing (FS) films were developed with natural polymers, namely chitosan (CHT) and hyaluronic acid (HA), being the catechol-functionalized hyaluronic acid (HA-DN) also included to provide wet adhesive properties. In order to obtain composite films, silver doped bioglass nanoparticles (Ag-BGs) were incorporated to promote bactericidal and bioactive properties, being tested four distinct formulations of FS films. Their surface morphology and topography, wettability, weight loss, swelling, mechanical, adhesion and bioactivity was analyzed. In particular, bioactivity tests revealed that upon immersion in simulated body fluid, there was the formation of a bone-like apatite layer. Moreover, upon $16 \mathrm{~h}$ in direct contact with Staphylococcus aureus and Escherichia coli cultures, these FS films exhibited a clear antibacterial effect. Therefore, such bioactive, antibacterial and adhesive free-standing films could potentially be used as temporary guided bone regeneration films, in particular to regenerate small bone defects and also periodontal tissues.
\end{abstract}

C) 2019 Elsevier B.V. All rights reserved.

\section{Introduction}

In recent decades, the scientific community has shown increasing interest in marine adhesives, particularly in mussel adhesive proteins, MAPs, since such proteins provide the role of cement which upon secretion become quickly solidified via chemical crosslinking into an insoluble plaque $[1,2]$. To this regard, it has been described that MAPs contain considerable concentrations of an amino acid, 3,4-dihydroxyphenyl-Lalanine (DOPA) [1,3-7], which presents the reactive catechol group (a benzene ring with two ortho-placed hydroxyl groups) that is primarily responsible for establishing strong bonds with various inorganic/organic surfaces, either in dry or wet environments [1,2,8-10]. Besides their versatility, some studies have also reported that bioadhesives inspired by MAPs are nontoxic when used as tissue adhesives or for

\footnotetext{
* Corresponding author at: 3B's Research Group, I3Bs - Research Institute on Biomaterials, Biodegradables and Biomimetics of University of Minho, Headquarters of the European Institute of Excellence on Tissue Engineering and Regenerative Medicine, AvePark - Parque de Ciência e Tecnologia, 4805-017 Barco, Guimarães, Portugal.

E-mail address: nalves@i3bs.uminho.pt (N.M. Alves).

1 Present address: Department of Chemistry, CICECO - Aveiro Institute of Materials, University of Aveiro, 3810-193 Aveiro, Portugal.
}

surface functionalization, which makes them promising materials for biomedical applications [2,11-13]. In addition, as a potential alternative to the synthesis of complex polypeptide or a variety of amino acid side chains, the catechol-functionalization has becoming a promising approach for designing biomimetic materials, since that functionality incorporates only the essential functional components of MAPs necessary for moisture-resistant adhesion [14-16]. In this context, different materials have been modified with catechol groups including synthetic (polyethylene glycol, polyvinyl alcohol) $[17,18]$ and natural polymers (chitosan, alginate and hyaluronic acid) $[13,19,20]$. Recently, our group have been focused on the potentiality of the catecholfunctionalized hyaluronic acid in the development of biodegradable multilayered systems with enhanced adhesive properties, where auspicious results were achieved envisaging tissue engineering purposes [8,21-24].

In this work, another biomimetic approach was used based on natural polymers, namely chitosan (CHT) and hyaluronic acid (HA). Chitosan is a linear polysaccharide with glucosamine and $N$-acetyl glucosamine units linked by $\beta-1,4$ glycosidic bonds [25], that it is only soluble in acidic solution $[26,27]$. CHT is frequently used in biomedical research due to the remarkable properties, such as biodegradability, 
biocompatibility, non-toxicity, low immunogenicity, anti-tumor effects and bacteriostatic/fungistatic characteristics [28,29]. On the other hand, HA is constituted by $N$-acetyl-D-glucosamine and D-glucuronate with $\beta-\mathrm{L}-4$ and $\beta-\mathrm{L}-3$ linkages $[8,30,31]$, and it can be found in several organs and in connective tissues of mammals, such as the synovial fluid, skin and vitreous body [32,33]. Furthermore, HA has influence in cell migration, adhesion and proliferation, being useful in the biomedical field, due to its important role in wound healing and lubricity [34].

Layer-by-Layer ( $\mathrm{LbL}$ ) technique was used since it is a versatile way to produce films, presenting many advantages, such as simplicity, cost-effectivity, flexibility, efficiency and reproducibility [35-37]. LbL is based on different charged species (polyelectrolytes) that are sequentially deposited onto a substrate [38]. This technique has been used to develop materials for distinct biomedical applications [39-43], namely wound healing [41,43], drug delivery [41,42] and biosensors manufacturing [39]. In a previous work of our group [8], a LbL coating containing CHT and hyaluronic acid modified with dopamine (HA-DN) was produced. These LbL films had higher adhesion strength, compared with the ones that did not contain catechol-modified polymer [8]. Similar findings were found in other recent works developed by our group, where LbL systems were constructed combining CHT, HA or HA-DN $[8,23,24]$ and bioactive glass nanoparticles (BGs) $[21,44]$ or silverdoped bioglass nanoparticles (Ag-BGs) [22]. Furthermore, these coatings with HA-DN presented high cellular adhesion, proliferation and viability [8,21-24] and, in accordance with Zhang and co-workers, these multilayer systems with CHT and HA-DN enhanced the osteoblast proliferation [45].

In the present work, new multifunctional free-standing (FS) films were proposed for guided bone regeneration, consisting in the incorporation of a quaternary formulation $\left[\mathrm{SiO}_{2}-\mathrm{CaO}-\mathrm{P}_{2} \mathrm{O}_{5}-\mathrm{Ag}_{2} \mathrm{O}=\right.$ 56:30:4:10\%mol] of silver doped bioglass nanoparticles, AgBGs, in the build-up of antibacterial and adhesive naturally-based FS films. These Ag-BGs were previously optimized and characterized by our group [46,47], revealing bioactive and antimicrobial properties that could be interesting to prevent recurrent post-surgical infections. On one hand, it has been established that nanoparticles composed by $\mathrm{SiO}_{2}, \mathrm{CaO}$ and $\mathrm{P}_{2} \mathrm{O}_{5}$ induced an apatite-like layer formation [48-50]. Furthermore, it has been generally evidenced that the presence of silver cations allows antimicrobial activity and a reduction of microbial infection [50-59]. As far as we know, this is the first time that FS films based on natural polymers and Ag-BGs that are simultaneously bioactive, antimicrobial and with adhesive properties are developed. Based in previous findings from the group [36,43,60,61], these FS films were post-processed through genipin crosslinking, since this crosslinker has also a natural origin and is non-cytotoxic [62-64], in order to obtain LbL films with reinforced physicochemical and mechanical properties. To investigate the potential of these nanostructured FS films for biomedical applications, and particularly for guided bone regeneration, their physicochemical, mechanical and adhesive properties were characterized in detail, as well as their bioactive and antibacterial effects under physiologicalsimulated conditions.

\section{Materials and methods}

\subsection{Materials}

Chitosan medium molecular weight (CHT, $N$-deacetylation degree of $80 \%$, molecular weight of $770 \mathrm{kDa}$ ), hyaluronic acid sodium salt from Streptococcus equi (HA, molecular weight of $595 \mathrm{kDa}$ ), dopamine hydrochloride (DN), $N$-(3-Dimethylaminopropyl)- $N^{\prime}$-ethylcarbodiimide hydrochloride (EDC, purum, $\geq 98.0 \%$ (AT)), dialysis tubing, benzoylated avg. flat width $32 \mathrm{~mm}$ (1.27 in.), ammonium phosphate dibasic, calcium nitrate tetrahydrate $99 \%$, ethanol absolute, ammonia water (ammonium hydrogen phosphate $98 \%$, maximum of $33 \% \mathrm{NH}_{3}$ ), sodium chloride $(\mathrm{NaCl})$, sodium of hydrogen carbonate $\left(\mathrm{NaHCO}_{3}\right)$, magnesium chloride hexahydrate $\left(\mathrm{MgCl}_{2} \cdot 6 \mathrm{H}_{2} \mathrm{O}\right)$, calcium chloride $\left(\mathrm{CaCl}_{2}\right)$, sodium sulfate $\left(\mathrm{Na}_{2} \mathrm{SO}_{4}\right)$, Tris(hydroxymethyl)-aminomethan (Tris buffer, $\left(\mathrm{CH}_{2} \mathrm{OH}\right)_{3} \mathrm{CNH}_{2}$ ), 2-(4-(2-hydroxyethyl)-1-piperazinyl) ethanesulfonic acid (HEPES, $\mathrm{C}_{8} \mathrm{H}_{18} \mathrm{~N}_{2} \mathrm{O}_{4} \mathrm{~S}$ ), hydrochloric acid $(\mathrm{HCl})$ and silver nitrate $\left(\mathrm{AgNO}_{3}\right)$ were acquired from Sigma-Aldrich (St. Louis, MO, USA). Tetraethyl orthosilicate (TEOS, 99.90\%) was purchased by Merck KGaA (Darmstadt, Germany). Nitric acid monohydrate (69\%), potassium chloride $(\mathrm{KCl})$, acetone and 2-propanol were obtained by VWR International (UK). Sodium hydroxide $(\mathrm{NaOH})$ was purchased from Fisher Chemical (Fisher Scientific UK, Leics, UK) and hydrogen peroxide 30\% (w/v) was obtained from Panreac AppliChem (Darmstadt, Deutschland). Sodium of hydrogen carbonate $\left(\mathrm{NaHCO}_{3}\right)$, dipotassium hydrogen phosphate trihydrate $\left(\mathrm{K}_{2} \mathrm{HPO}_{4} \cdot 3 \mathrm{H}_{2} \mathrm{O}\right)$ and calcium chloride $\left(\mathrm{CaCl}_{2}\right)$ were purchased from Merck (Merck Sharp \& Dohme Corp., Kenilworth, NJ, USA). Genipin was purchased by Wako (Wako Pure Chemical Industries, Ltd., Osaka, Japan). For microbial tests, Mueller-Hinton agar (MHA) medium was purchased from ThermoScientific (Thebarton, SA, Australia) and standardized cultures of Staphylococcus aureus (ATCC 29213) and Escherichia coli (ATCC 25922) with $1.5 \times 10^{8}$ CFU were purchased from the American Type Culture Collection (Manassas, VA, USA).

\subsection{Synthesis of hyaluronic acid-dopamine conjugate (HA-DN)}

HA was modified with the catechol groups of dopamine hydrochloride, called hyaluronic acid-dopamine conjugate (HA-DN), following the experimental procedure already described in a previous work [22], which was based in the protocol proposed by Lee and co-workers [7] with some modifications. Based on the UV-Vis spectrophotometry characterization, the HA-DN conjugate synthesized following the mentioned procedure [22] exhibited a substitution degree around 22\% (see Fig. S1).

\subsection{Production of silver doped bioglass nanoparticles (Ag-BGs)}

Silver doped bioglass nanoparticles with medium silver content [ $\mathrm{SiO}_{2}-\mathrm{CaO}-\mathrm{P}_{2} \mathrm{O}_{5}-\mathrm{Ag}_{2} \mathrm{O}$ (mol\%):56-30-4-10] were produced using a quick alkali-mediated sol-gel methodology optimized by our group [47], which was modified considering some procedures for synthesis of silver doped bioglass nanoparticles already reported in literature $[50,56,65]$. Briefly, at room temperature, osmotized water was added to TEOS and, then, added together with ethanol absolute. The $\mathrm{pH}$ value of this solution was adjusted to 2 with $2 \mathrm{M}$ nitric acid solution and the reaction mixture was kept stirring for $1 \mathrm{~h}$ to produce a solution A. Then, for preparation of the solution $\mathrm{B}$, calcium nitrate tetrahydrate, ammonium phosphate dibasic and silver nitrate were added to osmotized water and the $\mathrm{pH}$ value was adjusted to 11.5 with ammonium hydroxide solution, and this reaction mixture was kept under stirring for $1 \mathrm{~h}$. Under smooth stirring, the solution A was slowly added to solution B drop-by-drop and, simultaneously, the $\mathrm{pH}$ value of solution B was maintained at 11.5 using ammonia hydroxide solution. The final solution was kept stirring for $48 \mathrm{~h}$, and after washing three times with osmotized water, the precipitated gel particle was thermally treated with $100{ }^{\circ} \mathrm{C} / \mathrm{h}+580{ }^{\circ} \mathrm{C}, 1 / 2 \mathrm{~h}$ in a furnace, to eliminate organic residues and to obtain the Ag-BG powder.

\subsection{Free-standing films production}

In similar conditions of a previous work [44], fresh polyelectrolyte solutions were prepared with CHT, HA and HA-DN in $0.15 \mathrm{M} \mathrm{NaCl}$ solution to obtain a final concentration of $2 \mathrm{mg} \cdot \mathrm{mL}^{-1}$, while the final concentration of Ag-BGs suspension in $0.15 \mathrm{M} \mathrm{NaCl}$ was $2.5 \mathrm{mg} \cdot \mathrm{mL}^{-1}$. Attending the solubility of CHT in acidic solutions, the CHT solution was prepared in $0.15 \mathrm{M} \mathrm{NaCl}$ with $1 \%(\mathrm{v} / \mathrm{v}$ ) acetic acid. These PE solutions were prepared under stirring overnight and, immediately before the LbL construction, their $\mathrm{pH}$ value was adjusted to 5.5. The solution $0.15 \mathrm{M} \mathrm{NaCl}$ with the $\mathrm{pH}$ adjusted to 5.5 was used as the washing solution. It should be mentioned that the AgBG suspension was frequently 
dispersed in ultrasonic waterbath (DT100H SONOREX, Bandelin electronic GmbH \& Co. KG, Berlin, Germany) around 15 min to avoid the aggregation and precipitation of nanoparticles during LbL deposition. For the production of FS membranes, polypropylene (PP) films were used as a substrate and four distinct formulations with 300 layers were prepared, as shown in Fig. 1, using a dipping robot specially designed for the automatic fabrication of multilayers. After drying at room temperature, these membranes were easily detached from the substrate and, then, they were crosslinked with genipin following the procedure described by Silva and co-workers [60]. In particular, free-standing films were immersed in $1 \mathrm{mg} \cdot \mathrm{mL}^{-1}$ of genipin solution, dissolved in DMSO/ sodium acetate buffer $(0.15 \mathrm{M} \mathrm{NaCl})$, overnight at $37^{\circ} \mathrm{C}$. The resulting films were then washed with sodium acetate buffer $(0.15 \mathrm{M} \mathrm{NaCl}$, $\mathrm{pH}$ 5.5) during $30 \mathrm{~min}$ and then with DW during $1 \mathrm{~h}$. Finally, the crosslinked FS films were dried during 1 day at room temperature.

\subsection{Fourier Transform Infrared (FT-IR) spectroscopy}

Fourier Transform infrared spectroscopy was used to analyze the crosslinked free-standing films. The results were obtained using the FT-IR (Infrared spectrometer-Jasco), in the attenuated total reflectance (ATR), transmission mode. The FT-IR spectra were recorded from 600 to $4000 \mathrm{~cm}^{-1}$.

\subsection{Atomic force microscopy (AFM)}

Atomic force microscopy imaging was performed to characterize the topography of both surfaces (bottom and top) from FS films, using as AFM Dimension Icon (Bruker, USA) controlled by the NanoScope V (Bruker, USA). Three images $\left(10 \times 10 \mu \mathrm{m}^{2}\right)$ were obtained from each FS film condition using a PeakForce Tapping $®$ based image optimization technique, ScanAsyst ${ }^{\circledR}$ in air and at room temperature, and a silicon probe (ScanAsyst-AIR) with a triangular shape, a nominal spring constant of $0.4 \mathrm{~N} \cdot \mathrm{m}^{-1}$ and a nominal resonant frequency of $70 \mathrm{kHz}$. From each AFM image, the main surface roughness parameters - root mean square roughness $(\mathrm{Rq})$, arithmetic roughness ( $\mathrm{Ra})$ and maximum roughness (Rmax) - were evaluated using NanoScope Analysis software (v1.5, Bruker, USA).

\subsection{Scanning electron microscopy coupled with energy dispersive X-ray spectroscopy (SEM-EDS)}

The morphology of both surfaces of the FS films were characterized using the High-Resolution Field Emission Scanning Electron Microscope with Focused Ion Beam, FIB-SEM (AURIGA COMPACT, ZEISS) and also the Scanning Electron Microscope, SEM, with EDS (JSM-6010 LV, JEOL, Japan) coupled with dispersive X-ray spectroscopy (INCAx-Act,
PentaFET Precision, Oxford Instruments) equipment, operating at $15 \mathrm{kV}$ accelerating voltage. All samples were previously coated with a thin gold layer, using a sputter coater 108A (Cressington, UK).

\subsection{X-ray diffraction (XRD)}

An AXS D8 Discover (Bruker, USA) equipment was used for this characterization, with $\mathrm{Cu}-\mathrm{K} \alpha$ radiation $(\lambda=1.54060 \AA)$, scanning range from $15^{\circ}$ to $60^{\circ}$ at a speed of $0.04^{\circ} \cdot \mathrm{s}^{-1}$. The analysis for phase identification was performed using analytical software EVA. The crystalline phases were indexed using the ICDD-2015 database (International Center for Diffraction Data).

\subsection{Thermogravimetric analysis (TGA)}

Thermogravimetric measurements were performed in order to evaluate the amount of Ag-BGs present in the FS films, using a TA Q500 equipment (TA Instruments, USA) and spending around $4 \mathrm{mg}$ of FS film per experiment. All tests were performed under nitrogen atmosphere with a temperature range between $40{ }^{\circ} \mathrm{C}$ to $800{ }^{\circ} \mathrm{C}$, at a rate of $10{ }^{\circ} \mathrm{C} \cdot \mathrm{min}^{-1}$.

\subsection{Water contact angle (WCA) measurements}

OCA15plus goniometer equipment (DataPhysics, Germany) was used to perform the contact angle measurements onto both sides of the films, i.e., "top" corresponds to the top of the film and the "bottom" corresponds to the surface film in contact with the substrate, which was always a CHT layer. The measurements were performed using the sessile drop method, in which a drop of $3 \mu \mathrm{L}$ of ultrapure water was deposited on the surfaces by a syringe, and immediately after the water drop contacted the surface, images were acquired and analyzed using the SCA20 software (DataPhysics, Germany). For each condition characterized, at least three images were acquired, corresponding to six values of water contact angle.

\subsection{Tensile and adhesion tests}

Tensile strength and also lap-shear adhesive strength were performed using a universal electromechanical testing equipment (Instron 5543 , USA), equipped with a $1 \mathrm{kN}$ load cell, under the tensile mode. For this mechanical characterization, all samples were cut with similar dimensions: $0.6 \mathrm{~cm}$ of width, $3.0 \mathrm{~cm}$ of length and a gauge length of $1.2 \mathrm{~cm}$. For each sample, the thickness of the dried samples was measured three times $(n=3)$ and in wet state, samples were previously immersed in PBS during $60 \mathrm{~min}$. The measurements were taken under a loading speed of $1.5 \mathrm{~mm} \cdot \mathrm{min}^{-1}$, for the dry samples and
Formulation 1

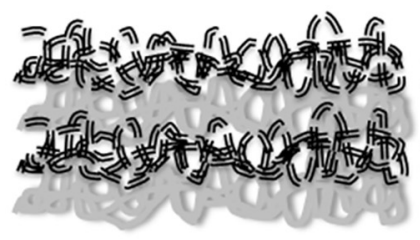

HA

CHT

HA CHT

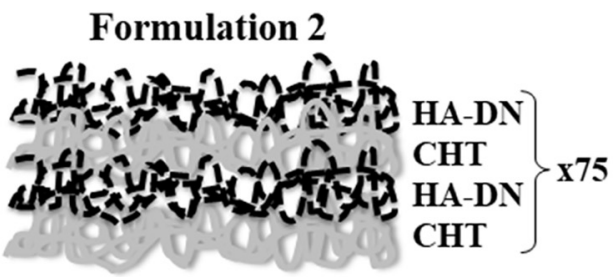

Formulation 3

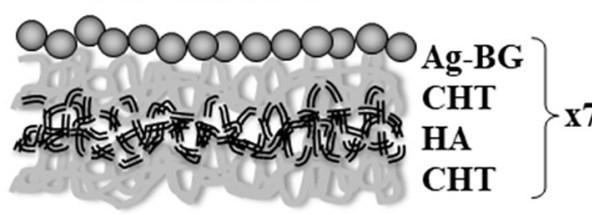

Formulation 4

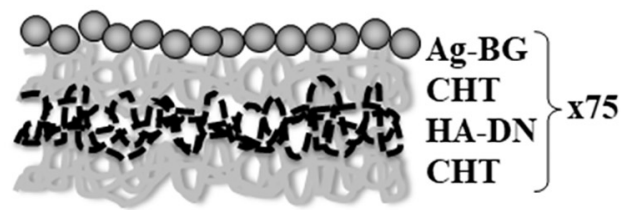

Fig. 1. Schematic illustration of distinct formulations developed for the studied free-standing films. 
$0.5 \mathrm{~mm} \cdot \mathrm{min}^{-1}$ for the wet samples. Based on the experimental stressstrain curves, the main mechanical parameters - ultimate tensile strength (UTS, MPa), tensile Young's modulus (E, MPa) and strain at break $(\varepsilon, \%)$ - were calculated. Additionally, the lap-shear stress tests were performed following the ASTM D1002 standard. Briefly, the FS films were soaked in PBS solution and cut with $5 \mathrm{~mm}$ width and $15 \mathrm{~mm}$ length, then they were put in contact with an overlapping area of $3.75 \times 5 \mathrm{~mm}^{2}$ and low-pressed between two glass slides overnight. Finally, prepared samples were tested under the same conditions described for the wet samples and the lap shear strength was determined from the maximum of the experimental stress-strain curves. All experimental data are presented as mean \pm standard deviation using at least five tested specimens per condition.

\subsection{In vitro bioactivity studies}

The four distinct formulations of FS films were immersed in a modified-simulated body fluid solution (m-SBF $1.5 \times$ ) at $37{ }^{\circ} \mathrm{C}$ for 14 days. This solution was prepared following the Oyane and coworkers procedures $[66,67]$, by dissolving sodium chloride $(\mathrm{NaCl})$, sodium sulfate $\left(\mathrm{Na}_{2} \mathrm{SO}_{4}\right.$, Panreac), magnesium chloride hexahydrate $\left(\mathrm{MgCl}_{2} \cdot 6 \mathrm{H}_{2} \mathrm{O}\right)$, di-Potassium hydrogen phosphate trihydrate $\left(\mathrm{K}_{2} \mathrm{HPO}_{4} \cdot 3 \mathrm{H}_{2} \mathrm{O}\right)$, calcium chloride $\left(\mathrm{CaCl}_{2}\right)$, potassium chloride $(\mathrm{KCl})$, sodium hydrogen carbonate $\left(\mathrm{NaHCO}_{3}\right)$, sodium carbonate $\left(\mathrm{Na}_{2} \mathrm{CO}_{3}\right)$, sodium hydroxide $(\mathrm{NaOH})$ and 2-(4-(2-hydroxyethyl)-1-piperazinyl) ethanesulfonic acid $\left(\mathrm{C}_{8} \mathrm{H}_{18} \mathrm{~N}_{2} \mathrm{O}_{4} \mathrm{~S}\right)$ in UPW at $36.5^{\circ} \mathrm{C}$ and with the final $\mathrm{pH}$ adjusted to 7.4. The free-standing films were put into a substrate of poly(propylene) holders with a window of $7 \mathrm{~mm} \times 7 \mathrm{~mm}$ and immersed, during 14 days in $10 \mathrm{~mL}$ of $\mathrm{SBF}$ at $37^{\circ} \mathrm{C}$. After being removed from $\mathrm{m}$-SBF $1.5 \mathrm{x}$, the films were washed with DW and left to dry at room temperature overnight. These films were further characterized in order to evaluate the formation of apatite by SEM with EDS (JSM6010 LV, JEOL, Japan) coupled with dispersive X-ray spectroscopy (INCAx-Act, PentaFET Precision, Oxford Instruments) and XRD analysis conducted with AXS D8 Discover equipment (Bruker, USA).

\subsection{Swelling behavior}

To determine the swelling behavior of the produced FS films, they were soaked in PBS ( $\mathrm{pH}=7.4$ ) at $37{ }^{\circ} \mathrm{C}$ along different time periods $(t$ $=0,5 \mathrm{~min}, 15 \mathrm{~min}, 30 \mathrm{~min}$ and $1 \mathrm{~h}$ to $7 \mathrm{~h}$ ). Firstly, all films $(n=3)$ were weighted in dry state, $\mathrm{Wd}$. Then, after each time-point, samples were taken from PBS solution, the excess of solution was carefully removed from the samples using filter paper, and the swollen films were immediately weighted, Ws. So, swelling percentage (or water uptake) was measured following the Eq. (1):

Swelling $(\%)=((\mathrm{Ws}-\mathrm{Wd}) / \mathrm{Wd}) * 100$

where: Ws = weight of swollen films and Wd = weight of dried films.

\subsection{Weight loss (WL)}

In order to determine the degradation behavior of these FS films ( $n$ $=3$ ), similarly with the tests performed for swelling behavior, samples were soaked in PBS for different time points, namely $t=7,14,21$ and 28 days, at $37^{\circ} \mathrm{C}$. All films were weighted before, Wi, and after each time point, Wf. After each timepoint, samples $(n=3)$ were removed from the PBS solution, washed in UPW and dried at $37^{\circ} \mathrm{C}$, and finally weighted. The percentage of weight loss (WL) of the FS films was calculated using the Eq. (2):

$\mathrm{WL}(\%)=((\mathrm{Wi}-\mathrm{Wf}) / \mathrm{Wi}) \times 100 \%$

where: $\mathrm{Wi}=$ initial dry weight of the sample and $\mathrm{Wf}=$ final dry weight after each timepoint.

\subsection{Microbiological study}

To study the inhibition of bacterial growth, the LbL films were placed in a Mueller-Hinton agar plate inoculated with $1.5 \times 10^{8} \mathrm{CFU}$ of a standard culture of Staphylococcus aureus and Escherichia coli (OD600 of approximately 0.1 ) and incubated during $16 \mathrm{~h}$ at $37^{\circ} \mathrm{C}$. The formation of inhibition zone surrounding the free-standing film was used as indicator of antibacterial behavior.

\subsection{Statistical analysis}

All data obtained were represented as mean \pm standard deviation with at least three replicates. Statistical analyses were made using one-way ANOVA followed by Tukey's test (GraphPad Prism 6.0 for Windows), since the population was normally distributed, otherwise it was mentioned. Statistical significance was accepted for a $\left({ }^{*}\right) p<0.05,\left({ }^{* *}\right) p$ $<0.01$.

\section{Results and discussion}

The build-up of the proposed four conditions of FS films was successful conducted, however the native films were not stable in distilled water and PBS solution. To overcome this drawback, all FS films were crosslinked with $1 \mathrm{mg} \cdot \mathrm{mL}^{-1}$ genipin solution. Photographs of the macroscopic morphology of the native and crosslinked LbL films are shown in Fig. S2. Through the analysis of Fig. S2A1-D1, it can be seen that F1 and F2 (without Ag-BGs) are transparent, whereas LbL films of F3 and F4 are opaque. So, similarly with Rodrigues et al. findings [44], it was confirmed that the incorporation of $\mathrm{Ag}-\mathrm{BG}$ s clearly altered the optical properties of the FS films. In the case of Fig. S2A2-D2, as expected, it was observed that the crosslinked reaction with genipin changed the color of the FS films, from the transparent white to the dark blue color. In fact, genipin has been used as a crosslinker agent because it is a natural molecule extracted from the gardenia fruit, which provides that dark blue coloring $[64,68]$. Besides its coloring effect, genipin presents significant lower cytotoxicity, when comparing with other crosslinking agents, like glutaraldehyde [64,69].

The FT-IR results of the crosslinked free-standing films and the control (native films) are shown in Fig. 2.

Fig. 2 shows the characteristic bands of chitosan (CHT): the band at $3267 \mathrm{~cm}^{-1}$ corresponds to the amine and hydroxyl groups [69]. Furthermore, bands at 1392 and $1565 \mathrm{~cm}^{-1}$ corresponds to the amide II of group $(\mathrm{O}=\mathrm{C}-\mathrm{N}-\mathrm{H})$ [60]. At $926 \mathrm{~cm}^{-1}$ to $1151 \mathrm{~cm}^{-1}$ there are the vibrational bands of CHT [41,69-71] and bands at 1281,1026 and $1078 \mathrm{~cm}^{-1}$ are attributed to the presence of $\mathrm{OH}-$, $\mathrm{C}-\mathrm{O}$ and $\mathrm{C}-\mathrm{N}$ stretching [69], respectively. At 1620 and $1660 \mathrm{~cm}^{-1}$ and between 1630 and $1700 \mathrm{~cm}^{-1}$ correspond to $\mathrm{C}=0$ bands and amide I of CHT [41,71], respectively. The characteristic peaks of $\mathrm{HA}$ are detected at $3383 \mathrm{~cm}^{-1}$, which corresponds to the $\mathrm{OH}-$ [72], also detectable in a range of 3350 to $3250 \mathrm{~cm}^{-1}$. The methylene group appears around 2940 and $2920 \mathrm{~cm}^{-1}$ and amide bonds stretching $(C=0)$ are detectable in a range of 1700 to $1250 \mathrm{~cm}^{-1}$. The peak at $1560 \mathrm{~cm}^{-1}$ corresponds to $\mathrm{N}-\mathrm{H}$ groups and the peak on $1100 \mathrm{~cm}^{-1}$ corresponds to ethers groups (-C-O-C) [73]. Furthermore, the $\mathrm{C}-\mathrm{O}$ and $\mathrm{C}-\mathrm{O}-\mathrm{C}$ stretching modes are detected at $1132 \mathrm{~cm}^{-1}$ [41]. It is also possible to identify various vibrational modes of Ag-BGs, namely $\mathrm{O}-\mathrm{H}$ stretching vibration at $3430 \mathrm{~cm}^{-1}$ and $1630 \mathrm{~cm}^{-1}$, due to the presence of water [74,75]. Finally, around 1045 and $1051 \mathrm{~cm}^{-1}$, there is the Si-O-Si asymmetric stretching vibration $[50,56,74,75]$. FTIR spectra of crosslinked films are slightly different than the uncrosslinked ones, essentially because there is an increase in the transmission through the crosslinked samples unlike the uncrosslinked ones, due to the interactions between the ester groups of genipin and the amine groups $(\mathrm{N}-\mathrm{H})$ of $\mathrm{CHT}[60,62]$. These changes are detected in the characteristic bands of amide I and II of CHT, leading to the 


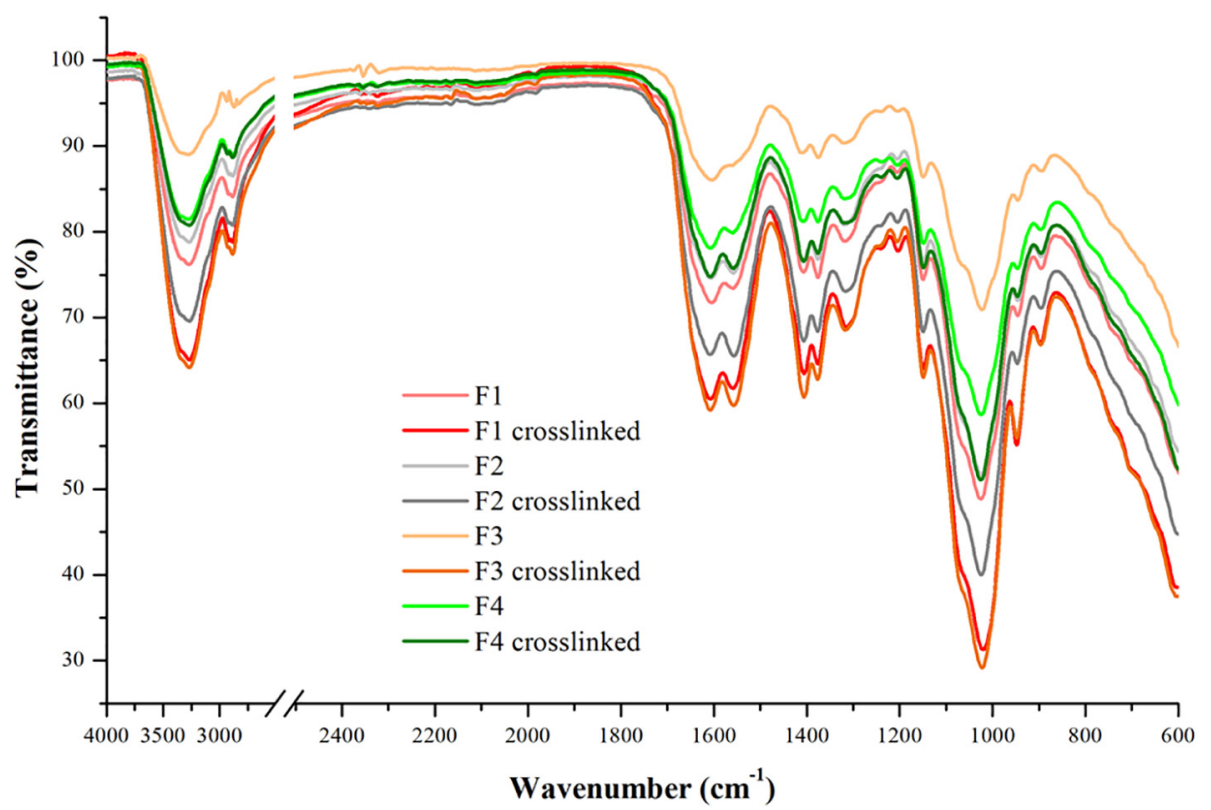

Fig. 2. FT-IR results of the crosslinked free-standing films crosslinked with genipin $\left(1 \mathrm{mg} \cdot \mathrm{mL}^{-1}\right)$.

formation of amide bonds [60]. Furthermore, at $1410-1560 \mathrm{~cm}^{-1}$ and $1575 \mathrm{~cm}^{-1}$ there is an increase in transmittance, due to the formation of alkene groups and a decrease of amine peak, detectable at $1575 \mathrm{~cm}^{-1}[60,62]$.
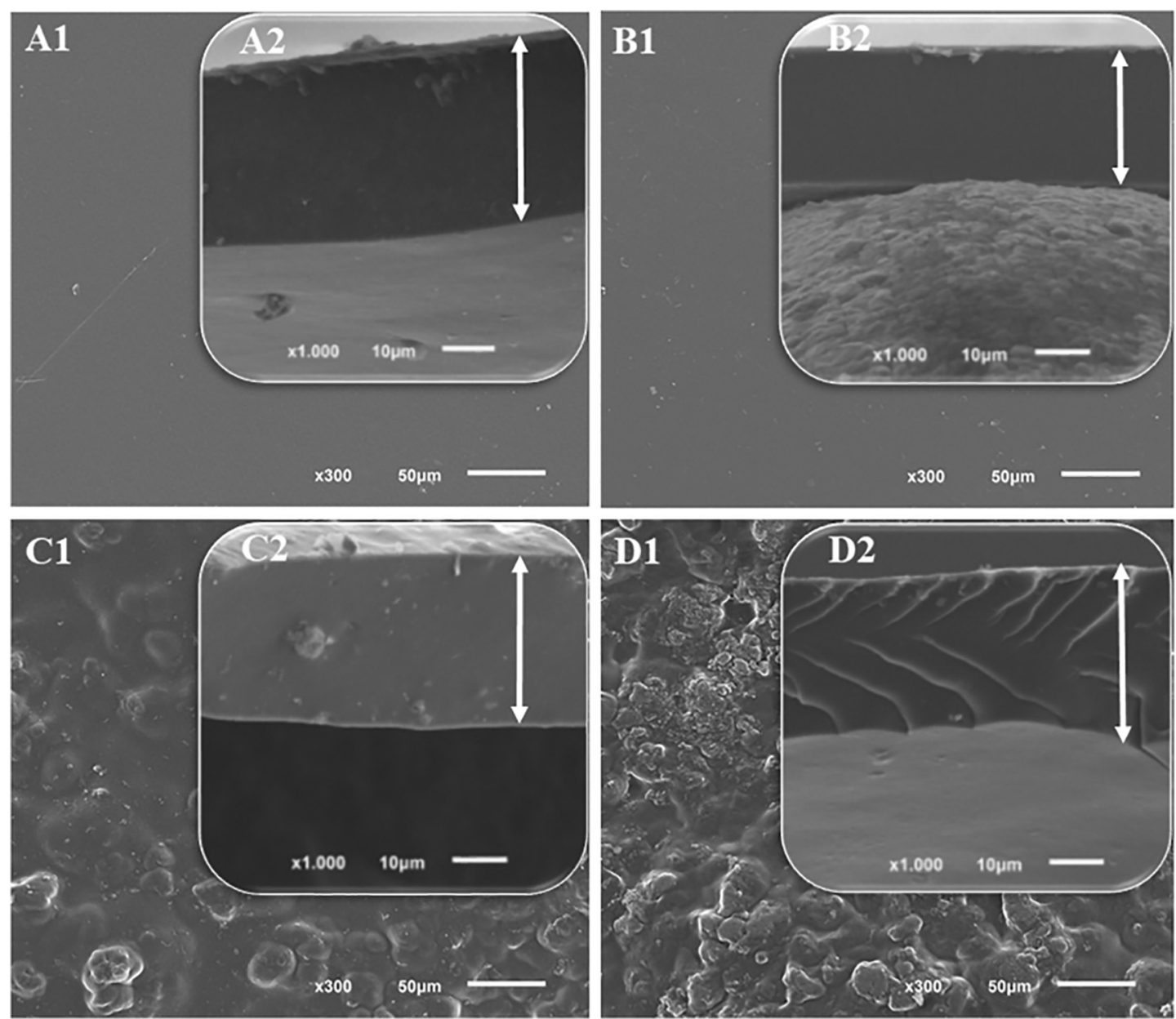

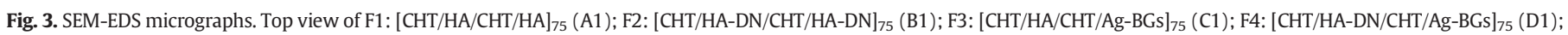

and cross-section views of F1 (A2); F2(B2); F3(C2) and F4(D2).

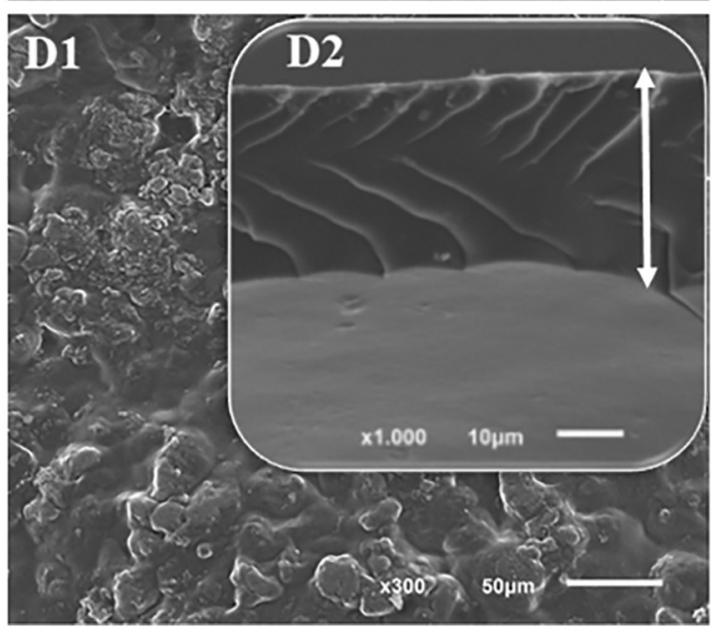

Fig. 3 shows the micrographs obtained for surface morphology of distinct FS films and their respective cross-sections.

Fig. 3-A1 and Fig. 3-B1 show a homogeneous and smooth surface, in contrast with Fig. 3-C1 and -D1, where it can be seen the adsorbed 
nanoparticles in the end-layer, and also Ag-BGs across the film construction can be seen in Fig. 3-C2 and -D2. The cross-sections of these FS membranes do not present significant differences, showing a compact organization of the layers. However, it is possible to detect some differences in their thickness: the F1 and F3 were the thicker ones, presenting a thickness of $27.08 \pm 1.91 \mu \mathrm{m}$ and $24.42 \pm 1.70 \mu \mathrm{m}$, respectively. Then, essentially due to the presence of catechol groups from HA-DN that contributes for a more compact LbL structure, the F3 and F2 presented slightly lower thicknesses, $23.33 \pm 2.60 \mu \mathrm{m}$ and 21.25 $\pm 1.25 \mu \mathrm{m}$, respectively. These findings are in agreement with some previous works based on the QCM experiments, where the antimicrobial bioinspired film ([CHT/HA-DN/CHT/AgBG]) was thicker than its control ([CHT/HA/CHT/AgBG]) [22], but comparing with a similar LbL construction without bioactive glass nanoparticles ([CHT/HA-DN]) [8], those antimicrobial coatings presented a lower thickness.

In order to evaluate the surface morphology of the produced FS films at a high resolution, AFM imaging analysis was performed and these results were shown in Fig. S3. Moreover, from this imaging technique were determined the roughness parameters presented in Fig. 4, the root mean square $(\mathrm{Rq})$, the average roughness $(\mathrm{Ra})$ and the maximum roughness (Rmax) are lower for the bottom side (in contact with the PP substrate) than for the top surface.

Also, when comparing all Rq, Ra and Rmax for the bottom surface of F1 and F2, it can be noticed that they have similar values due to the contact with the substrate. For the top side, the F1 presents higher values when compared to F2. The present data were corroborated in a previous work [8], where higher roughness was obtained for coatings with CHT and HA in comparison with those containing CHT and HA-DN. Regarding F3 and F4, for the bottom side, we can see that the surface roughness is lower than the obtained values for the top side, as they are in contact with the substrate, but they present higher values than F1 and F2, probably due to some diffusion processes. Regarding the top surface of F3 and F4, it can be seen that they present higher Ra, Rq and Rmax values than the control ones (Fig. 4). This can be justified by the presence of Ag-BGs in the end-layer, which can lead to a higher roughness. Furthermore, the texture presented by the top side of F4 (Fig. 4-H) is consistent with Ag-BGs agglomerates. Additionally, F3 presents higher Ra and Rq values when compared with F4. In fact, the top surface in F3 presents nanoparticles' agglomerates, meaning that these nanoparticles aren't uniformly distributed on their surface, implying that F3 is more heterogeneous than F4. Effectively, a rough surface is useful for cell adhesion, because there are more anchor points and more available surface area for protein adsorption [76].
Concerning the thermogravimetric analysis (Fig. 5), for all formulations, the thermal degradation of organic fraction ( $\mathrm{CHT}$ and HA) takes place at a lower temperature than that of pure $\mathrm{HA}\left(220^{\circ} \mathrm{C}\right)$ and $\mathrm{CHT}$ $\left(290{ }^{\circ} \mathrm{C}\right)$ [77], since the obtained results are around $213^{\circ} \mathrm{C}$ for $\mathrm{HA}$ and $278{ }^{\circ} \mathrm{C}$ for CHT. TGA thermograms also show that around $60{ }^{\circ} \mathrm{C}$ to 80 ${ }^{\circ} \mathrm{C}$ there is a weight loss, and this is related to the evaporation of water and alcohol. Moreover, around $540{ }^{\circ} \mathrm{C}$ and $550{ }^{\circ} \mathrm{C}$ there is the decomposition of the unreacted $\mathrm{Ca}\left(\mathrm{NO}_{3}\right)_{2}$ [50]. The results also evidence some differences in their final weight loss: for $\mathrm{F} 1$ was of $31.82 \%$, $35.45 \%$ for $\mathrm{F} 2,41.02 \%$ for $\mathrm{F} 3$ and $50.68 \%$ for $\mathrm{F} 4$, verifying higher weight loss for composite formulations (F3 and F4). In addition, discounting the final weight loss at $800^{\circ} \mathrm{C}$ for $\mathrm{F} 3$ and $\mathrm{F} 4$ and their respective controls (F1 and F2), respectively, the incorporation of Ag-BGs was 15\% for F3 and $16 \%$ for $\mathrm{F} 4$. These results are into the range described by Rodrigues et al. [44], where polysaccharide/bioactive glass nanoparticles FS films revealed an incorporation of nanoparticles between $56 \%$ and $16 \%$. So, the obtained $\mathrm{AgBGs}$ incorporation is quite satisfactory, attending that these nanoparticles tend to agglomerate, and they were incorporated on each LbL cycle with a previous ultrasonic treatment, in order to maximize the Ag-BGs adsorption.

Since the mechanical properties are important to understand if a material can be used in biomedical purposes, i.e., if it is able to resist in biological environments [78], in the present work, the tensile mechanical properties were shown in Fig. 6, corresponding to the values obtained for distinct membranes in both dry and wet states. It should be mentioned that the mechanical characterization in dry state was also included, because during surgical procedure these FS membranes should withstand highest stresses at dry state (immediately before absorbing the body fluids) [79-81] and the transition dry-to-wet must be also evaluated.

In the dry state, F1 and F2 presented significantly higher Young's modulus values (1035.66 $\pm 384.48 \mathrm{MPa}$ and $1209.45 \pm 651.64 \mathrm{MPa}$, respectively) than those formulations with Ag-BGs, where F3 and F4 evidenced correspondingly $218.76 \pm 96.57 \mathrm{MPa}$ and $66.57 \pm 12.18 \mathrm{MPa}$ (Fig. 6-C). These values are in line with those reported by Mota et al. [82], where significant differences were also found for pure chitosan and composite membranes in dry and wet conditions. In fact, F3 and F4 showed a brittle behavior, due to their inorganic component (AgBGs), evidencing an early rapid increase in their strength and, for this reason, their structure disrupted critically leading to the premature failure of these formulations. In the wet state, the stiffness of membranes showed an opposite trend, being the formulations with Ag-BGs the ones that evidenced higher Young's modulus values (Fig. 6-D), which

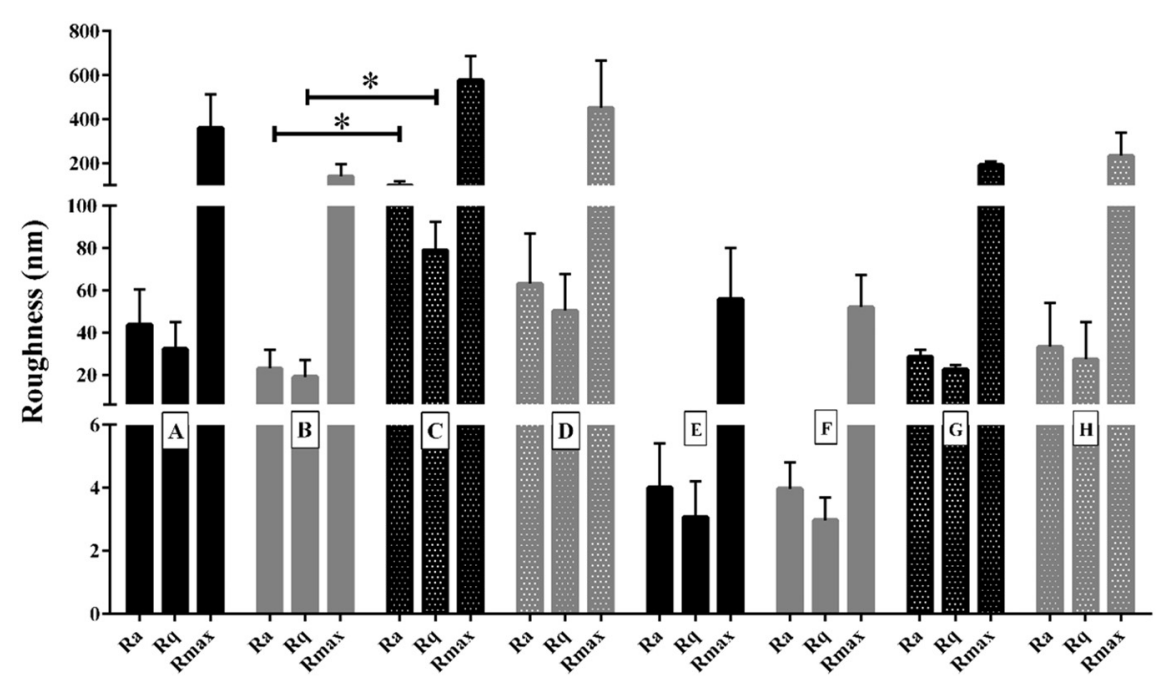

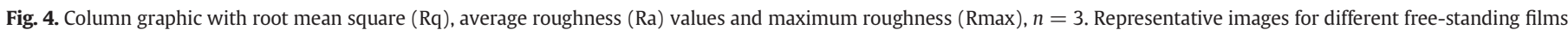
formulations: top and bottom views $(10 \mu \mathrm{m} \times 10 \mu \mathrm{m})$ (one-way ANOVA, $p<0.05\left[{ }^{*}\right]$ ). 

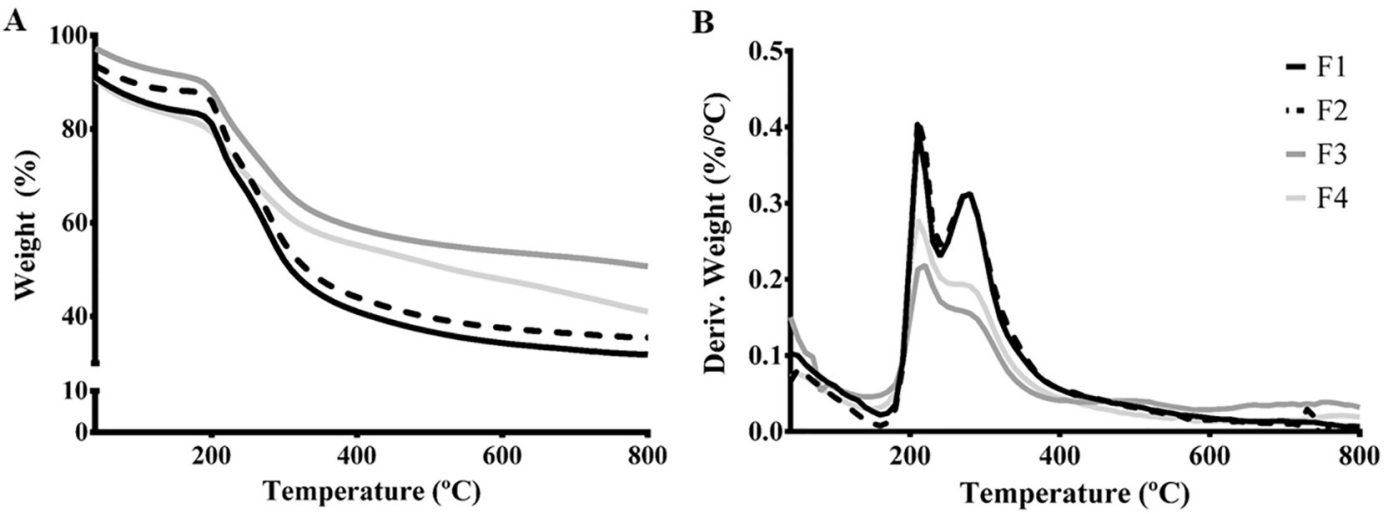

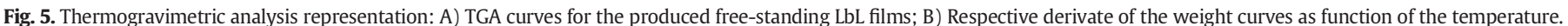

could be justified by the plasticizing effect of PBS [78]. Moreover, the ultimate tensile stress and the Young's modulus decreased in wet conditions comparing to the dry ones, which are in accordance with some findings already reported about the mechanical resistance of some
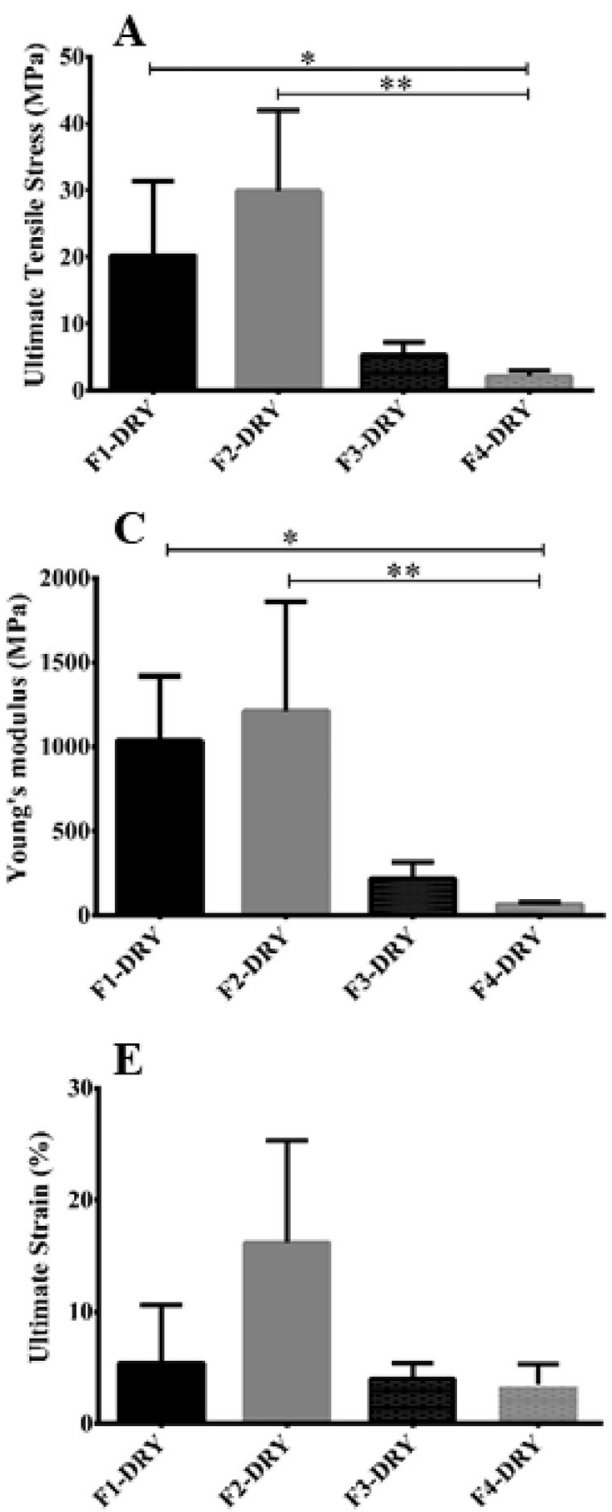

polymeric and composite membranes [82,83] and also regarding the mechanical behavior of commercial resorbable membranes for periodontal regeneration $[82,84,85]$. In the wet state, formulations containing Ag-BGs (F3 and F4) presented higher Young's modulus values, but

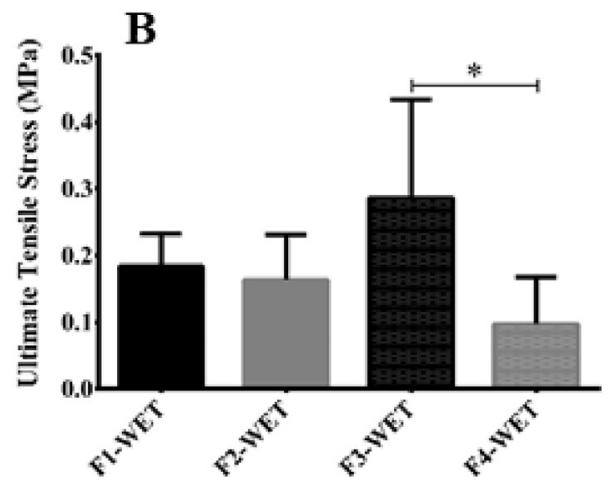

D
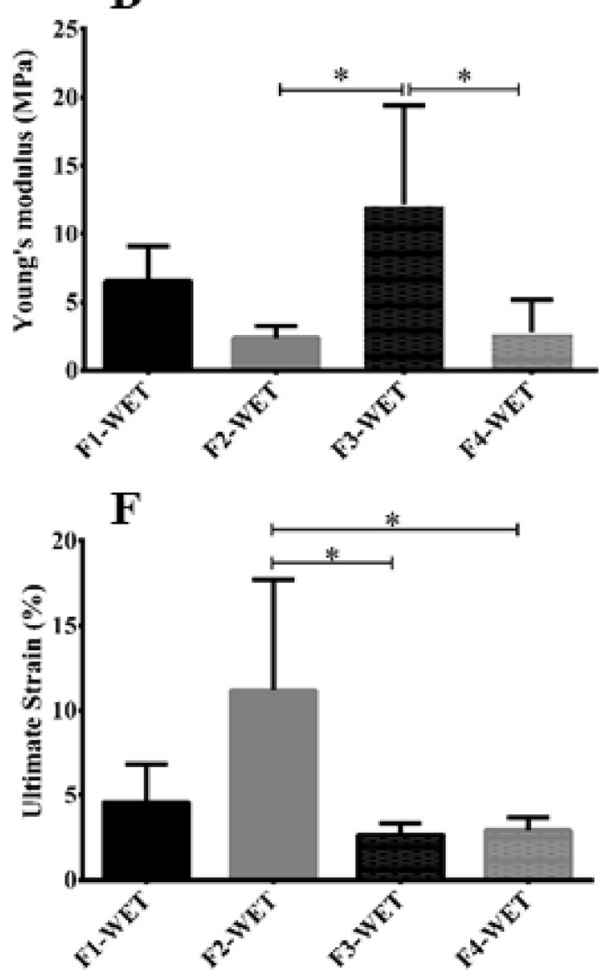

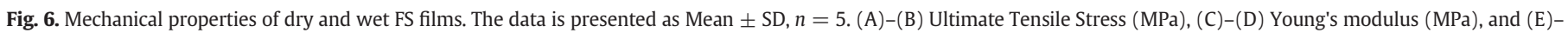
(F) Ultimate strain (\%) [one-way ANOVA, $p<0.05\left[{ }^{*}\right], p<0.01$ [ $\left.{ }^{* *}\right]$. 
for the ultimate strain $\left(\varepsilon_{\mathrm{B}}\right)$ they presented lower values than the control ones. Essentially, polymeric conditions (F1 and F2) are more ductile, presenting higher strain values (Fig. 6-F), but they present lower stiffness, implying lower Young's modulus values (Fig. 6-D) and also subsequent lower ultimate tensile strength values (Fig. 6-B). Moreover, in agreement with previous findings reported by other LbL works $[60,86]$, all formulations were stiffer than the uncrosslinked ones. Regarding the mechanical performance of the films in wet state, since tensile strength values between 1.6 and $22.5 \mathrm{MPa}$ and Young's Modulus between 10 and $70.9 \mathrm{MPa}[84,85,87]$ have been reported with biodegradable membranes for guided bone regeneration, it can be seen that the developed films presented values with the same order of magnitude of the ones typically used in the clinics for the envisaged applications.

Adhesion tests were also conducted to evaluate the influence of the end-layer in the adhesive strength of the developed films, and the adhesion strengths determined for each condition were shown in Fig. 7.

In fact, the produced free-standing films have three different endlayers, namely HA, HA-DN and Ag-BGs. Unsurprisingly, as it was represented in Fig. 7, the higher adhesion strength was obtained for F2: [CHT/ HA-DN/CHT/HA-DN] 75 (448.61 $\pm 68.07 \mathrm{kPa})$, due to its adhesive endlayer (HA-DN), being followed by F1: [CHT/HA/CHT/HA $]_{75}(222.02 \pm$ $108.10 \mathrm{kPa}), \mathrm{F} 4:$ [CHT/HA-DN/CHT/Ag-BGs $]_{75}(234.55 \pm 67.56 \mathrm{kPa})$ and F3: [CHT/HA/CHT/Ag-BGs $]_{75}(202.73 \pm 71.19 \mathrm{kPa})$. Regarding the effect of HA-DN and Ag-BGs on the adhesive strength of the FS films, herein, it was found similar findings reported in previous works developed by our group [8,21,22], where also different combinations of adhesive LbL coatings were studied. Firstly, Neto and co-workers [8] showed that the adhesive strength for films with HA-DN was higher when compared with the control one, where HA was the end-layer. Furthermore, the same author showed that the adhesive strength increased for CHT/ HA-DN films with higher concentrations of catechol groups, and also that the adhesive force increased with an increasing number of layers [88]. In another study involving LbL coatings, it was demonstrated that formulation containing BGs and HA-DN presented higher adhesive strength, unlike the control condition without adhesive layer [21]. Although, the adhesive strength is lower for coatings with BGs when comparing to the control ones [21] and herein, similar trend was found comparing the results for F2 versus F4. In fact, the presence of HA-DN allows to enhance the adhesive strength when compared with the corresponding control films. Nevertheless, for F3 and F4, there was no significant difference between their adhesive strength. Comparing these results with those presented in a previous work about polysaccharide/BGs FS membranes, where adhesive strength values between 90 and $150 \mathrm{kPa}$ were reported [44], it should be mentioned that the present study exhibited films with enhanced adhesive strength. Moreover, in a more recent work where bioinspired FS adhesive films were developed

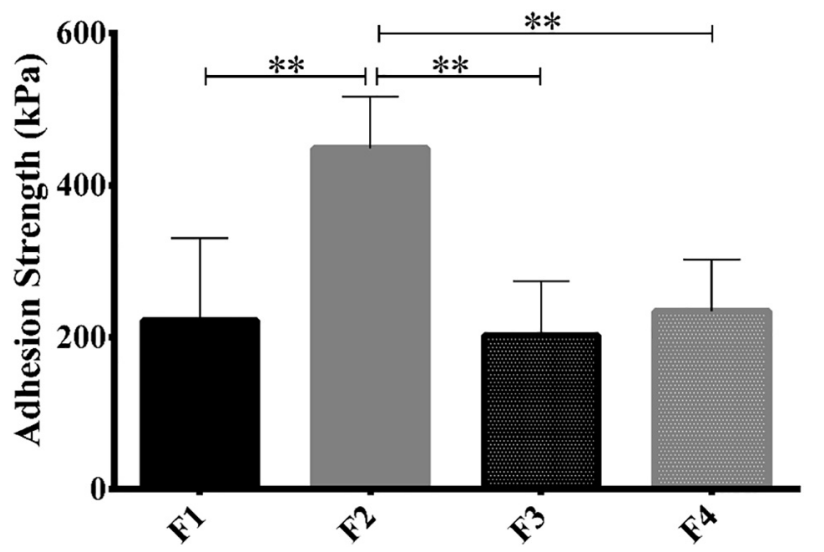

Fig. 7. Adhesive strength of the free-standing films. Data shown is represented as Mean \pm Standard Deviation (SD), $n=5$ at least. Statistical analysis performed using One-way ANOVA $p<0.05[*], p<0.01$ [**]. with chitosan and hyaluronic acid, Wang et al. [83] reported similar excellent wet adhesion strength for FS films with 300 layers, reaching the maximum adhesion around $400 \mathrm{kPa}$. Herein, the polymeric formulation F2 presented higher adhesive strength ( $448.61 \pm 68.07 \mathrm{kPa})$ followed by the composite formulation F4 $(234.55 \pm 67.56 \mathrm{kPa})$, the polymeric formulation F1 (222.02 $\pm 108.10 \mathrm{kPa})$ and finally, the composite F3 $(202.73 \pm 71.19 \mathrm{kPa})$. Besides the adhesion of these FS films were relatively low than our previous results for LbL coatings [8,21,22], the maximum adhesion obtained was 2.6 times higher than the adhesion strength of marine mussels measured on glass substrate (171 \pm $65 \mathrm{kPa}$ ) [89] and the lower adhesion value was only 1.2 times higher.

Attending the expected application of these FS films, it is clear from our results that the presence of catechol groups enhanced significantly their bioadhesiveness. For example, considering that the gold standard non-resorbable material for guided tissue regeneration membranes is dense polytetrafluoroethylene (d-PTFE) [87], the enhanced adhesion of the developed FS films could certainly help the implantation of these inert membranes in situ.

In order to investigate if the developed free-standing films present a bioactive character, they were immersed in SBF solution during 14 days, and XRD diffractograms were obtained before and after SBF immersion, being the experimental results shown in Fig. 8.

The XRD diffractograms represented in Fig. 8 showed that after immersion in SBF, for F1 and F2, there was no formation of hydroxyapatite on its surface, since they did not content inorganic component. However, for F3 and F4, it was observed a characteristic halo of the amorphous materials in the $2 \theta$ region from 15 to $35^{\circ}$. For the samples immersed during 7 days, some crystalline peaks appeared between $2 \theta$ $=15^{\circ}$ to $35^{\circ}$ are identified as hydroxyapatite $\left(\mathrm{Ca}_{5}\left(\mathrm{PO}_{4}\right)_{3}(\mathrm{OH})\right.$, Hexagonal, pattern: 01-089-4405), and the strongest lines corresponds to $2 \theta$ around $29^{\circ}$ and $32.9^{\circ}$. These results are similar to other works developed in our group [21,22], demonstrating the capacity of these freestanding films containing Ag-BGs to induce the formation of an apatite-like layer onto their surface. SEM micrographs, shown in Fig. S4 corroborated the in vitro bioactive character of the composite FS films. Besides the SEM images evidencing cauliflower-like apatite clusters, another indication of the development of an apatite precipitate in soaked samples is that the concentrations of Ca and P gradually increase as the concentration of Si decreases due to the dissolution of AgBGs. From Fig. S4, it was demonstrated that only composite formulations (F3 and F4) evidenced the formation of a calcium phosphate $(\mathrm{Ca}-\mathrm{P})$ layer on their surface, which corroborated the XRD pattern shown in Fig. 8. In contrast and unsurprisingly, F1 and F2 (Fig. S4-A,

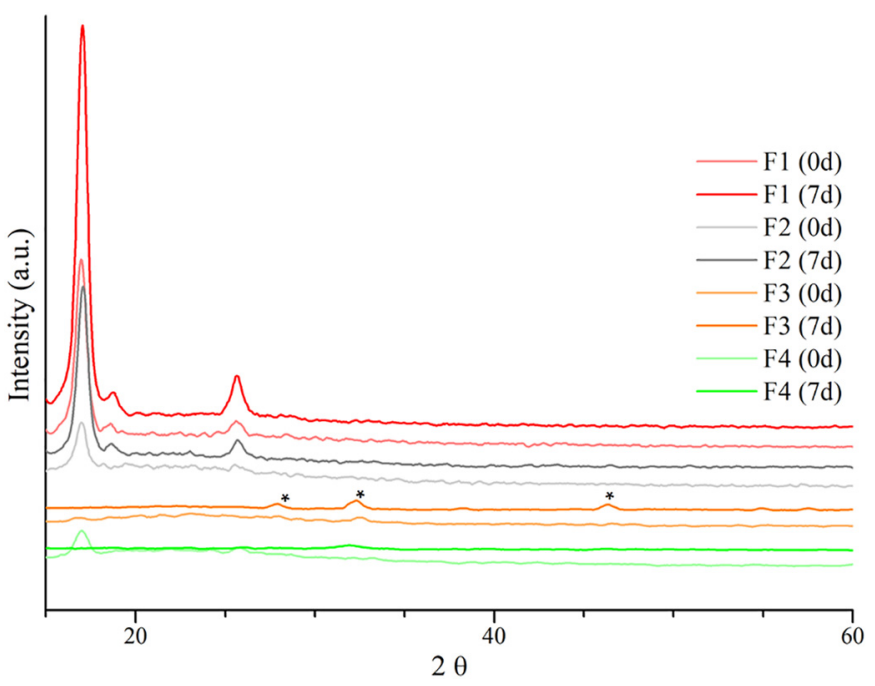

Fig. 8. XRD diffractograms for four different formulations of FS films with (7d) and without (Od) immersion in SBF solution. Typical crystalline peaks of apatite-like phase were indicated $\left(^{*}\right)$. 
B) there is no Ca-P layer, due to the absence of bioglass matrix on their constitution. Moreover, the EDS quantification (wt\%) presented only for formulations with bioactive behavior (F3 and F4) showed the presence of carbon $(\mathrm{C})$, oxygen $(\mathrm{O})$, sodium $(\mathrm{Na})$ and chloride $(\mathrm{Cl})$, due to the residues of sodium chloride solution used in the washing steps during the LbL assembly. More importantly, in agreement with a previous work [22], it was detected high amounts of calcium (Ca) and phosphorous $(\mathrm{P})$, due to the formation of a calcium-phosphate layer $(\mathrm{Ca}-\mathrm{P})$ for $\mathrm{F} 3$ and F4 (Fig. S4-C, D) and a decrease of silicon ( $\mathrm{Si}$ ), due to the dissolution of Ag-BGs. Furthermore, as expected for F3 and F4, EDS showed $\mathrm{Ca} / \mathrm{P}$ ratios which are closed to the stoichiometric composition of hydroxyapatite (1.67) [46,90]: 1.5 for both formulations with AgBGs, confirming their bioactivity potential of these LbL constructions, similarly with previous results obtained only for these AgBGs [46].

In order to evaluate the hydrophobicity/hydrophilicity of the developed FS films, the water contact angle (WCA) analysis was performed and these experimental results were shown in Fig. 9.

Hydrophilic materials have been described with lower water contact angles, i.e., angles below $90^{\circ}$, and in opposite way, hydrophobic materials are associated to higher WCA values $\left(>90^{\circ}\right)$ [91]. Based on the results presented in Fig. 9, it can be concluded that the WCA values were higher for the side of the films that was in contact with the PP substrate (bottom) and lower for the end-layer of the film (top). Particularly, the top side from F1 and F2 presented means WCA values of $44.36^{\circ} \pm 4.63^{\circ}$ and $64.98^{\circ} \pm 3.39^{\circ}$, respectively. However, Neto and co-workers [8] showed a different trend for WCA values, where [CHT/ $\mathrm{HA}]_{10}$ and $[\mathrm{CHT} / \mathrm{HA}-\mathrm{DN}]_{10}$ presented $77.36^{\circ} \pm 1.44^{\circ}$ and $73.34^{\circ} \pm$ $1.82^{\circ}$, respectively. The present work shows lower WCA values than in the previous work [8], mainly due to the increase of the number of layers on the produced FS films, which contributed to an improve on their hydrophilicity, and also due to the effect of genipin crosslinking, that also reduces the WCA values [88]. It is well-known that CHT, bottom side, presents hydrophobicity [60], and the obtained results are overall near or above $90^{\circ}$, except for F3, which had a WCA equal to $51.60^{\circ} \pm 9.33^{\circ}$. Concerning the top sides of F3 and F4, the obtained values revealed that the surfaces are hydrophilic and for F4 it is completely hydrophilic (WCA $=0^{\circ}$ ). The probable explanation for the difference between the WCA values for the top sides of F3 and F4 is the higher concentration of Ag-BGs on the surface of the last one, which implies a decrease in WCA value. Regarding this effect, Roohani-Esfahani et al. [92] developed a nanocomposite made by biphasic calcium phosphates, poly- $\varepsilon$-caprolactone and bioactive glass nanoparticles, and pure PCL showed a WCA value of $109.2^{\circ}$ that became more hydrophilic with the addition of bioglass nanoparticles (WCA decreased to $54.7^{\circ}$ ) [92]. In fact, in accordance with Roohani-Esfahani and co-workers' findings, overall WCA values decreased with the presence of silver-doped bioglass nanoparticles.

The water uptake was also assessed by swelling analysis at $t=0$, $5 \mathrm{~min}, 15 \mathrm{~min}, 30 \mathrm{~min}$ and $1 \mathrm{~h}$ to $7 \mathrm{~h}$, Fig. S5.

In accordance with some previous findings [44,93], these FS films swelled rapidly during the first 5 min in PBS solution and then, they stabilized reaching the swelling equilibrium ( $t=30 \mathrm{~min}$ ). Afterwards their final water uptake value was defined by their composition. Polymeric formulations (F1 and F2) swelled around 150 to 450\%, but F3 and F4, that containing Ag-BGs, showed a relative lower swelling than the polymeric ones, around 150 to $230 \%$. One possible reason to explain this lower water uptake for formulations with Ag-BGs is that with the addition of nanoparticles, the space between the polyelectrolyte chains is lower than the for controls ones, implying lower available space for water absorption. This effect could be intensified by the genipin crosslinking, attending that those crosslinked FS films presented lower swelling values than the uncrosslinked ones [60,61], because the crosslinker also reduces the intermolecular space between polyelectrolyte chains [60].

Concerning the applicability of these free-standing films for tissue regeneration, it is crucial to perform longer degradation studies, to evaluate their stability and integrity along the time [94]. In this sense, degradation tests were performed during 28 days at $37^{\circ} \mathrm{C}$ by immersion of films in a PBS solution, since it simulates the saline environment of the human body, and the experimental results were represented in Fig. S6.

There was an increase of weight loss for all formulation until day 14 (except for F1), then it stabilized reaching the equilibrium. Moreover, it can be seen that the formulations containing Ag-BGs presented higher weigh loss rates, when compared with the control ones. Goh and coworkers [75] studied the change of $\mathrm{pH}$ over time for different
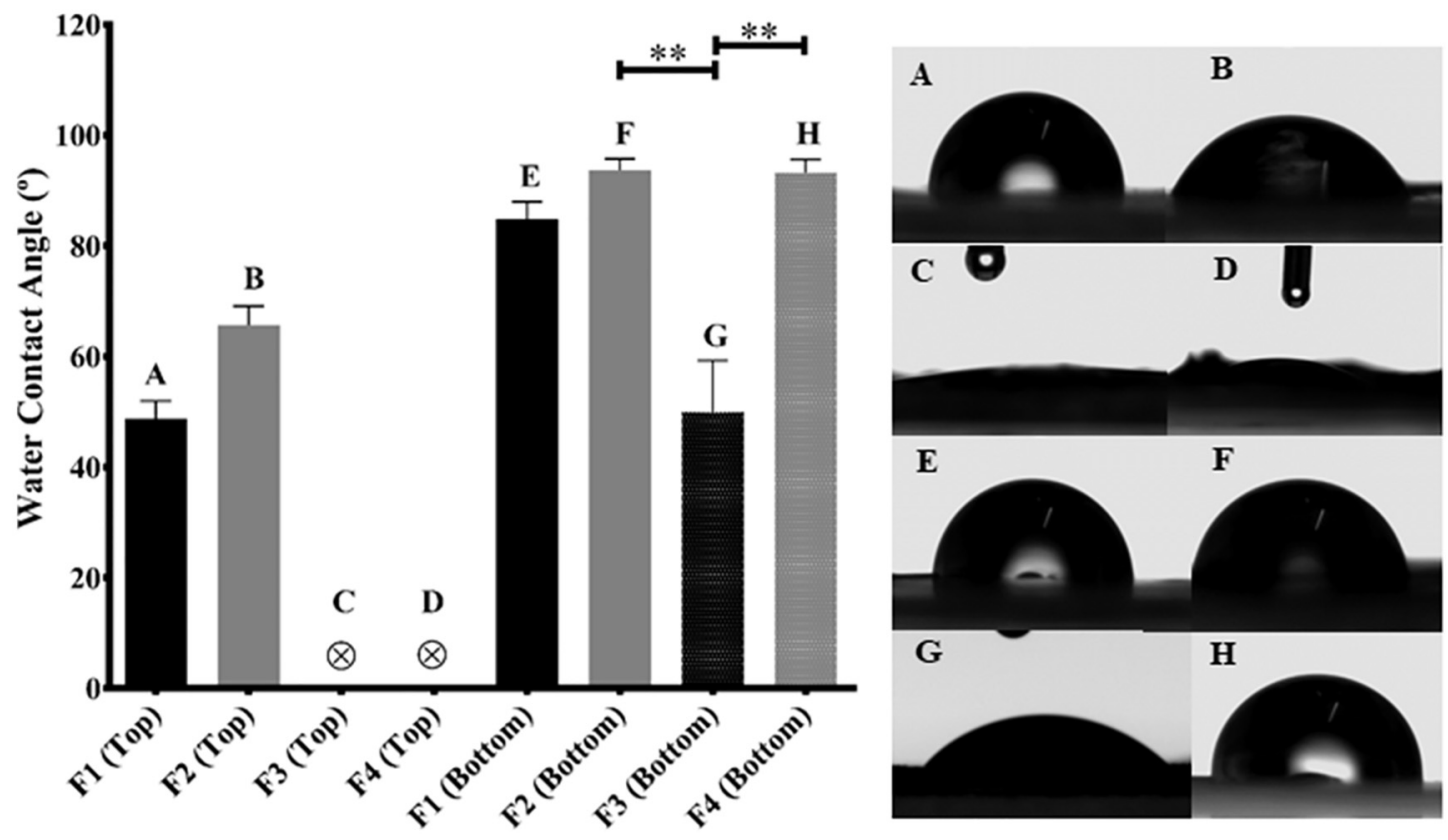

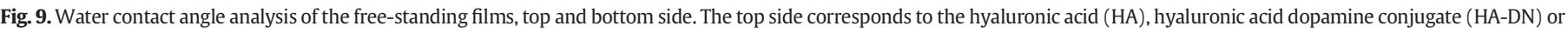

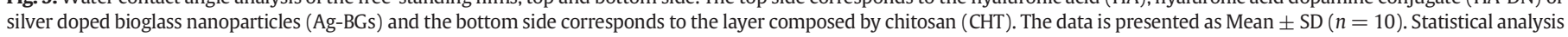
performed using One-way ANOVA, $p<0.01$ [**]. 
F1
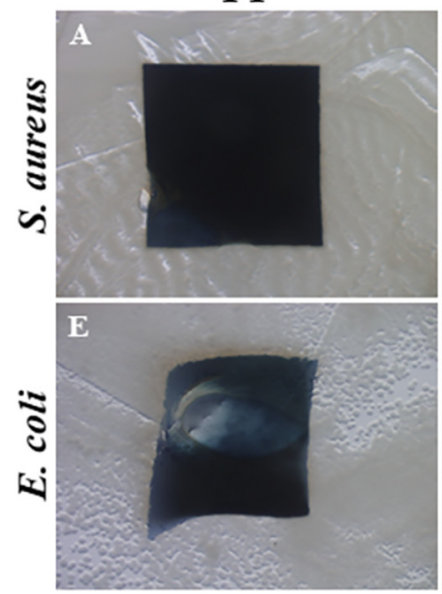

F2
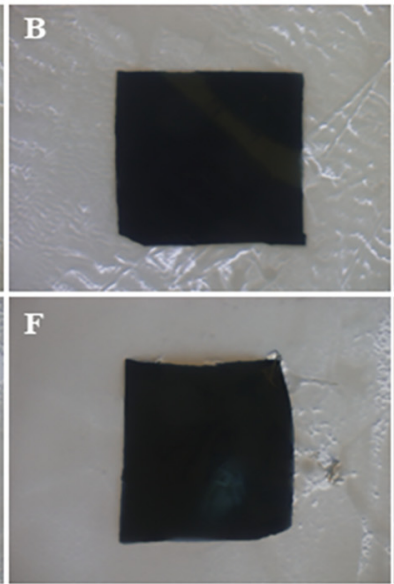

F3
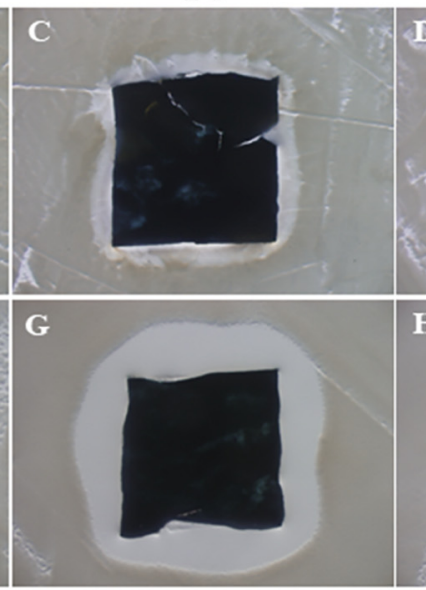

F4
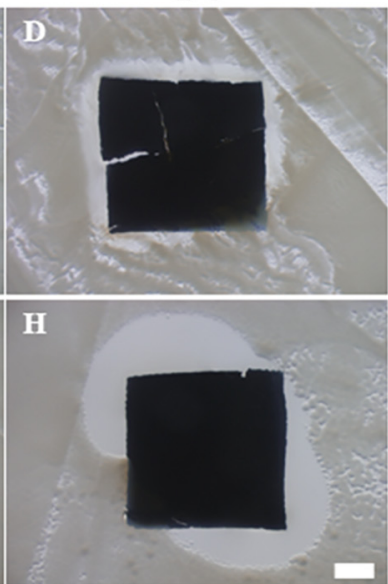

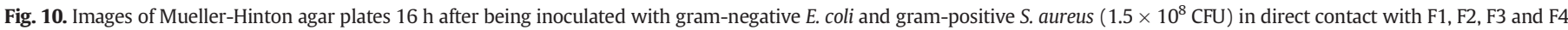
membranes incubated at $37^{\circ} \mathrm{C}$. Scale bar represents $1 \mathrm{~mm}$.

formulations of bioglass nanoparticles immersed in PBS solution, and their results showed a $\mathrm{pH}$ increase over time related with the $\mathrm{Ca}^{2+}$ ions released with $\mathrm{H}^{+}$ions present in the PBS solution. Probably, a high $\mathrm{pH}$ value and the silver ions $\left(\mathrm{Ag}^{+}\right)$released to the PBS solution could contribute to an accelerated degradation specifically for $\mathrm{F} 3$ and F4. In fact, it has been shown that silver ions are dissolved from AgBG rapidly (in hours), being also demonstrated that the $\mathrm{Ag}^{+}$release together with other bioglass species, namely calcium, phosphate and silicate, does not compromise the antibacterial properties of AgBGs [95-98].

Finally, the antimicrobial vulnerability of the produced films was also investigated through a qualitative way based on the disk diffusion methodology. Fig. 10 presents the representative images of Escherichia coli and Staphylococcus aureus cultures that were grown for $16 \mathrm{~h}$ in direct contact with different $\mathrm{FS}$ formulations.

The antibacterial properties of silver nanoparticles has been described as resulting from the silver ions release $[95,99,100]$, and the concrete antibacterial action of these silver ions has been described through different mechanisms already described elsewhere [46]. Summarily, it is believed that silver ions can react with the surface proteins of bacterial cell walls, promoting their metabolic pathway disorder [75,101], which could lead to the bacterial cell death; in other way, silver ions can also contribute for disruption of the bacterial membrane, followed by the entrance of $\mathrm{Ag}^{+}$into the cytoplasm, that can induce subsequent damages: silver ions can stimulate the production of reactive oxygen species, which cause critical damages to proteins, DNA, RNA synthesis, leading to the bacterial cell death [102].

Unsurprisingly, only F3 (Fig. 10-C, G) and F4 (Fig. 10-D, H) exhibited a bright inhibitory zone formed around membranes, evidencing their antibacterial action. In fact, these results were in accordance with the findings described in our previous works [46,47], where it was described that this antibacterial performance resulted from the leaching of ionic silver from the glass matrix. Moreover, since the silver ions could only be released from the powders through the ion exchange between $\mathrm{Ag}^{+}$and $\mathrm{H}_{3} \mathrm{O}^{+}$ from surrounding water, the release of $\mathrm{Ag}^{+}$is controlled by the rate of interdiffusion of these cations [52]. Probably due to that diffusioncontrolled mechanism that decreases the rate of $\mathrm{Ag}^{+}$release, the inhibitory zones formed around F3 and F4 membranes were relatively small, nevertheless these results are according with those already reported in literature $[22,46,47,52,53,75,95,100,103,104]$. In particular, similarly with a previous study of our group [22], where the antibacterial activity of LbL coatings with Ag-BGs was studied, in the present work it was also detected an inhibition zone that is not regular, probably because these FS membranes tend to rearrange their shape in wet state becoming not flat, which could affect the diffusion of silver ions from the membranes through the agar plate.

\section{Conclusions}

Four different LbL free-standing films based on CHT, HA, HA-DN and Ag-BGs were successfully developed. The incorporation of Ag-BGs on these FS films did not compromise their bioactivity, having induced the formation of a calcium-phosphate layer on their surface. Furthermore, adhesion tests revealed that the incorporation of HA-DN led to a significantly increase of the film adhesion strength. Microbiological studies confirmed that only formulations containing silver doped nanoparticles showed a promising bacterial growth inhibition. Besides their ability to induce hydroxyapatite on their surface, after immersion in SBF solution during 14 days, they presented an effective antibacterial activity against $E$. coli and $S$. aureus bacteria after $16 \mathrm{~h}$. F4 revealed to be the most promising resorbable FS polysaccharide composite configuration, since it combined three relevant functionalities for guided bone regeneration, bioactivity, enhanced adhesiveness and antibacterial properties, which can synergistically contribute for a successful regeneration. These adhesive FS films could be used as temporary guided bone regeneration films in small bone defects and periodontal tissues, and also as a medical dressings.

\section{Notes}

The authors declare no competing financial interest.

\section{Acknowledgments}

The authors acknowledge the Portuguese Foundation for Science and Technology (FCT) and the European program FEDER/COMPETE for the financial support through projects PTDC/BTM-MAT/28123/2017, PTDC/NAN-MAT/31036/2017 and the exploratory project MIT-EXPL/ BIO/0089/2017. ACV thanks Dr. Isabel Leonor (I3Bs/UM) for her valuable contribution in SEM and AFM analysis.

\section{Appendix A. Supplementary data}

Supplementary data to this article can be found online at https://doi. org/10.1016/j.ijbiomac.2019.04.102. 


\section{References}

[1] P. Podsiadlo, Z. Liu, D. Paterson, P.B. Messersmith, N.A. Kotov, Fusion of seashell nacre and marine bioadhesive analogs: high-strength nanocomposite by layerby-layer assembly of clay and L-3,4-dihydroxyphenylalanine polymer, Adv. Mater. 19 (2007) 949-955.

[2] H. Lee, N.F. Scherer, P.B. Messersmith, Single-molecule mechanics of mussel adhesion, Proc. Natl. Acad. Sci. U. S. A. 103 (2006) 12999-13003.

[3] H.G. Silverman, F.F. Roberto, Understanding marine mussel adhesion, Mar. Biotechnol. 9 (2007) 661-681.

[4] S.K. Madhurakkat Perikamana, J. Lee, Y.B. Lee, Y.M. Shin, E.J. Lee, A.G. Mikos, H. Shin, Materials from mussel-inspired chemistry for cell and tissue engineering applications, Biomacromol 16 (2015) 2541-2555.

[5] Y. Chan Choi, J.S. Choi, Y.J. Jung, Y.W. Cho, Human gelatin tissue-adhesive hydrogels prepared by enzyme-mediated biosynthesis of DOPA and Fe3+ ion crosslinking, J. Mater. Chem. B 2 (2014) 201-209.

[6] M. Cencer, Y. Liu, A. Winter, M. Murley, H. Meng, B.P. Lee, Effect of pH on the rate of curing and bioadhesive properties of dopamine functionalized poly(ethylene glycol) hydrogels, Biomacromol 15 (2014) 2861-2869.

[7] Y. Lee, H.J. Chung, S. Yeo, C.-H. Ahn, H. Lee, P.B. Messersmith, T.G. Park, Thermosensitive, injectable, and tissue adhesive sol-gel transition hyaluronic acid/pluronic composite hydrogels prepared from bio-inspired catechol-thiol reaction, Soft Matter 6 (2010) 977-983.

[8] A.I. Neto, A.C. Cibrao, C.R. Correia, R.R. Carvalho, G.M. Luz, G.G. Ferrer, G. Botelho, C. Picart, N.M. Alves, J.F. Mano, Nanostructured polymeric coatings based on chitosan and dopamine-modified hyaluronic acid for biomedical applications, Small 10 (2014) 2459-2469.

[9] J.J. Wilker, The iron-fortified adhesive system of marine mussels, Angew. Chem. Int. Edit. 49 (2010) 8076-8078.

[10] S.A. Burke, M. Ritter-Jones, B.P. Lee, P.B. Messersmith, Thermal gelation and tissue adhesion of biomimetic hydrogels, Biomed. Mater. 2 (2007) 203-210.

[11] H. Lee, B. Lee, P.B. Messersmith, A reversible wet/dry adhesive inspired by mussels and geckos, Nature (2007) 338-341.

[12] G. Westwood, T.N. Horton, J.J. Wilker, Simplified polymer mimics of cross-linking adhesive proteins, Macromol 40 (2007) 3960-3964.

[13] C. Lee, J. Shin, J.S. Lee, E. Byun, J.H. Ryu, S.H. Um, D.-I. Kim, H. Lee, S.-W. Cho, Bioinspired, calcium-free alginate hydrogels with tunable physical and mechanical properties and improved biocompatibility, Biomacromol. 14 (2013) 2004-2013.

[14] M. Yu, T.J. Deming, Synthetic polypeptide mimics of marine adhesives, Macromol 31 (1998) 4739-4745.

[15] H. Lee, S.M. Dellatore, W.M. Miller, P.B. Messersmith, Mussel-inspired surface chemistry for multifunctional coatings, Science 318 (2007) 426-430.

[16] H. Lee, K.D. Lee, K.B. Pyo, S.Y. Park, H. Lee, Catechol-grafted poly(ethylene glycol) for PEGylation on versatile substrates, Langmuir 26 (2010) 3790-3793.

[17] D.E. Fullenkamp, J.G. Rivera, Y.-k. Gong, K.H.A. Lau, L. He, R. Varshney, P.B. Messersmith, Mussel-inspired silver-releasing antibacterial hydrogels, Biomater. 33 (2012) 3783-3791.

[18] H.Y. Son, J.H. Ryu, H. Lee, Y.S. Nam, Bioinspired templating synthesis of metalpolymer hybrid nanostructures within 3D electrospun nanofibers, ACS Appl Mater. Interf. 5 (2013) 6381-6390.

[19] J.H. Ryu, S. Hong, H. Lee, Bio-inspired adhesive catechol-conjugated chitosan for biomedical applications: a mini review, Acta Biomater. 27 (2015) 101-115.

[20] H.-J. Park, Y. Jin, J. Shin, K. Yang, C. Lee, H.S. Yang, S.-W. Cho, Catecholfunctionalized hyaluronic acid hydrogels enhance angiogenesis and osteogenesis of human adipose-derived stem cells in critical tissue defects, Biomacromol 17 (2016) 1939-1948.

[21] S.J. Rego, A.C. Vale, G.M. Luz, J.F. Mano, N.M. Alves, Adhesive bioactive coatings inspired by sea life, Langmuir 32 (2016) 560-568.

[22] A.L. Carvalho, A.C. Vale, M.P. Sousa, A.M. Barbosa, E. Torrado, J.F. Mano, N.M. Alves, Antibacterial bioadhesive layer-by-layer coatings for orthopedic applications, J. Mater. Chem. B 4 (2016) 5385-5393.

[23] M.P. Sousa, J.F. Mano, Cell-adhesive bioinspired and catechol-based multilayer freestanding membranes for bone tissue engineering, Biomimetics 2 (2017) 19.

[24] M.P. Sousa, A.I. Neto, T.R. Correia, S.P. Miguel, M. Matsusaki, I.J. Correia, J.F. Mano, Bioinspired multilayer membranes as potential adhesive patches for skin wound healing, Biomater. Sci. 6 (2018) 1962-1975.

[25] N.M. Alves, J.F. Mano, Chitosan derivatives obtained by chemical modifications for biomedical and environmental applications, Int. J. Biol. Macromol. 43 (2008) 401-414.

[26] M. Rinaudo, Chitin and chitosan: properties and applications, Progr Polym. Sci. 31 (2006) 603-632.

[27] D.S. Couto, Z. Hong, J.F. Mano, Development of bioactive and biodegradable chitosan-based injectable systems containing bioactive glass nanoparticles, Acta Biomater. 5 (2009) 115-123.

[28] C. Shi, Y. Zhu, X. Ran, M. Wang, Y. Su, T. Cheng, Therapeutic potential of chitosan and its derivatives in regenerative medicine, J. Surg. Res. 133 (2006) 185-192.

[29] M. Dash, F. Chiellini, R.M. Ottenbrite, E. Chiellini, Chitosan-a versatile semisynthetic polymer in biomedical applications, Progr. Polym. Sci. 36 (2011) 981-1014.

[30] M. Morra, Engineering of biomaterials surfaces by hyaluronan, Biomacromol 6 (2005) 1205-1223.

[31] P. Kujawa, P. Moraille, J. Sanchez, A. Badia, F.M. Winnik, Effect of molecular weight on the exponential growth and morphology of hyaluronan/chitosan multilayers: a surface plasmon resonance spectroscopy and atomic force microscopy investigation, J. Am. Chem. Soc. 127 (2005) 9224-9234.
[32] J.F. Mano, G.A. Silva, H.S. Azevedo, P.B. Malafaya, R.A. Sousa, S.S. Silva, L.F. Boesel, J.M. Oliveira, T.C. Santos, A.P. Marques, N.M. Neves, R.L. Reis, Natural origin biodegradable systems in tissue engineering and regenerative medicine: present status and some moving trends, J. Royal Soc. Interf. 4 (2007) 999-1030.

[33] J.R. Fraser, T.C. Laurent, U.B. Laurent, Hyaluronan: its nature, distribution, functions and turnover, J Inter. Med. 242 (1997) 27-33.

[34] W.G. Pitt, R.N. Morris, M.L. Mason, M.W. Hall, Y. Luo, G.D. Prestwich, Attachment of hyaluronan to metallic surfaces, J. Biomed. Mater. Res. A 68 (2004) 95-106.

[35] J. Borges, J.F. Mano, Molecular interactions driving the layer-by-layer assembly of multilayers, Chem. Rev. 114 (2014) 8883-8942.

[36] J.M. Silva, A.R.C. Duarte, S.G. Caridade, C. Picart, R.L. Reis, J.F. Mano, Tailored freestanding multilayered membranes based on chitosan and alginate, Biomacromol 15 (10) (2014) 3817-3826.

[37] G.V. Martins, J.F. Mano, N.M. Alves, Nanostructured self-assembled films containing chitosan fabricated at neutral pH, Carbohydr. Polym. 80 (2010) 570-573.

[38] P.T. Hammond, Engineering materials layer-by-layer: challenges and opportunities in multilayer assembly, AICHE J. 57 (2011) 2928-2940.

[39] L. Han, Z.-M. Wang, X. Lu, L. Dong, C.-M. Xie, K.-F. Wang, X.-I. Chen, Y.-H. Ding, L.-T. Weng, Mussel-inspired adhesive and transferable free-standing films by selfassembling dexamethasone encapsulated BSA nanoparticles and vancomycin immobilized oxidized alginate, Coll. Surf. B Interf. 126 (2015) 452-458.

[40] M. Kohri, Y. Shinoda, H. Kohma, Y. Nannichi, M. Yamauchi, S. Yagai, T. Kojima, T. Taniguchi, K. Kishikawa, Facile synthesis of free-standing polymer brush films based on a colorless polydopamine thin layer, Macromol. Rapid Commun. 34 (2013) 1220-1224.

[41] S.G. Caridade, C. Monge, F. Gilde, T. Boudou, J.F. Mano, C. Picart, Free-standing polyelectrolyte membranes made of chitosan and alginate, Biomacromol 14 (2013) 1653-1660.

[42] A.L. Larkin, R.M. Davis, P. Rajagopalan, Biocompatible, detachable, and freestanding polyelectrolyte multilayer films, Biomacromol 11 (2010) 2788-2796.

[43] S.G. Caridade, C. Monge, J. Almodóvar, R. Guillot, J. Lavaud, V. Josserand, J.-L. Coll, J.F. Mano, C. Picart, Myoconductive and osteoinductive free-standing polysaccharide membranes, Acta Biomater. 15 (2015) 139-149.

[44] J.R. Rodrigues, N.M. Alves, J.F. Mano, Biomimetic polysaccharide/bioactive glass nanoparticles multilayer membranes for guided tissue regeneration, RSC Adv. 6 (2016) 75988-75999.

[45] X. Zhang, Z. Li, X. Yuan, Z. Cui, X. Yang, Fabrication of dopamine-modified hyaluronic acid/chitosan multilayers on titanium alloy by layer-by-layer selfassembly for promoting osteoblast growth, Appl. Surf. Sci. 284 (2013) 732-737.

[46] A.C. Vale, P.R. Pereira, A.M. Barbosa, E. Torrado, N.M. Alves, Optimization of silvercontaining bioglass nanoparticles envisaging biomedical applications, Mater. Sci. Eng. C 94 (2019) 161-168.

[47] A.C. Vale, A.L. Carvalho, A.M. Barbosa, E. Torrado, J.F. Mano, N.M. Alves, Novel antibacterial and bioactive silicate glass nanoparticles for biomedical applications, Adv. Eng. Mater. 20 (2018), 1700855.

[48] G.M. Luz, J.F. Mano, Preparation and characterization of bioactive glass nanoparticles prepared by sol-gel for biomedical applications, Nanotechn 22 (2011), 494014.

[49] G.M. Luz, J.F. Mano, Chitosan/bioactive glass nanoparticles composites for biomedical applications, Biomed. Mater. 7 (2012), 054104.

[50] A. Vulpoi, L. Baia, S. Simon, V. Simon, Silver effect on the structure of SiO2-CaOP2O5 ternary system, Mater. Sci. Eng. C 32 (2012) 178-183.

[51] Q.L. Feng, J. Wu, G.Q. Chen, F.Z. Cui, T.N. Kim, J.O. Kim, A mechanistic study of the antibacterial effect of silver ions on Escherichia coli and Staphylococcus aureus, J. Biomed. Mater. Res. 52 (2000) 662-668.

[52] M. Kawashita, S. Tsuneyama, F. Miyaji, T. Kokubo, H. Kozuka, K. Yamamoto, Antibacterial silver-containing silica glass prepared by sol-gel method, Biomater 21 (2000) 393-398.

[53] M. Catauro, M.G. Raucci, F. De Gaetano, A. Marotta, Antibacterial and bioactive silver-containing $\mathrm{Na} 2 \mathrm{O} \times \mathrm{CaO} \times 2 \mathrm{SiO} 2$ glass prepared by sol-gel method, J. Mater. Sci. Mater. Med. 15 (2004) 831-837.

[54] A. Balamurugan, G. Balossier, D. Laurent-Maquin, S. Pina, A.H. Rebelo, J. Faure, J.M. Ferreira, An in vitro biological and anti-bacterial study on a sol-gel derived silverincorporated bioglass system, Dent. Mater. 24 (2008) 1343-1351.

[55] G.A. Sotiriou, S.E. Pratsinis, Antibacterial activity of nanosilver ions and particles, Environ. Sci. Techn. 44 (2010) 5649-5654.

[56] A.M. El-Kady, A.F. Ali, R.A. Rizk, M.M. Ahmed, Synthesis, characterization and microbiological response of silver doped bioactive glass nanoparticles, Ceram. Int. 38 (2012) 177-188.

[57] S. Prabhu, E.K. Poulose, Silver nanoparticles: mechanism of antimicrobial action, synthesis, medical applications, and toxicity effects, Int. Nano Lett. 2 (2012) 32.

[58] S.A. Brennan, C. Ni Fhoghlu, B.M. Devitt, F.J. O'Mahony, D. Brabazon, A. Walsh, Silver nanoparticles and their orthopaedic applications, Bone Joint J. 97 (2015) 582-589.

[59] A.L. Gallo, F. Paladini, A. Romano, T. Verri, A. Quattrini, A. Sannino, M. Pollini, Efficacy of silver coated surgical sutures on bacterial contamination, cellular response and wound healing, Mater. Sci. Eng. C 69 (2016) 884-893.

[60] J.M. Silva, S.G. Caridade, N.M. Oliveira, R.L. Reis, J.F. Mano, Chitosan-alginate multilayered films with gradients of physicochemical cues, J. Mater. Chem. B 3 (2015) 4555-4568.

[61] J.M. Silva, S.G. Caridade, R.L. Reis, J.F. Mano, Polysaccharide-based freestanding multilayered membranes exhibiting reversible switchable properties, Soft Matter 12 (2016) 1200-1209.

[62] C. Chaubaroux, E. Vrana, C. Debry, P. Schaaf, B. Senger, J.-C. Voegel, Y. Haikel, C. Ringwald, J. Hemmerlé, P. Lavalle, F. Boulmedais, Collagen-based fibrillar multilayer films cross-linked by a natural agent, Biomacromol 13 (2012) 2128-2135.

[63] F. Gaudière, S. Morin-Grognet, L. Bidault, P. Lembré, E. Pauthe, J.-P. Vannier, H. Atmani, G. Ladam, B. Labat, Genipin-cross-linked layer-by-layer assemblies: 
biocompatible microenvironments to direct bone cell fate, Biomacromol 15 (2014) 1602-1611.

[64] A.L. Hillberg, C.A. Holmes, M. Tabrizian, Effect of genipin cross-linking on the cellular adhesion properties of layer-by-layer assembled polyelectrolyte films, Biomater 30 (2009) 4463-4470.

[65] J.R.J. Delben, O.M. Pimentel, M.B. Coelho, P.D. Candelorio, L.N. Furini, F. Alencar dos Santos, F.S. de Vicente, A.A.S.T. Delben, Synthesis and thermal properties of nanoparticles of bioactive glasses containing silver, J. Therm. Anal. Calorim. 97 (2009) 433.

[66] A. Oyane, H.-M. Kim, T. Furuya, T. Kokubo, T. Miyazaki, T. Nakamura, Preparation and assessment of revised simulated body fluids, J. Biomed. Mater. Res. A 65 (2) (2003) 188-195.

[67] A. Oyane, K. Onuma, A. Ito, H.-M. Kim, T. Kokubo, T. Nakamura, Formation and growth of clusters in conventional and new kinds of simulated body fluids, J. Biomed. Mater. Res. A 64 (2003) 339-348.

[68] M. Mekhail, K. Jahan, M. Tabrizian, Genipin-crosslinked chitosan/poly-L-lysine gels promote fibroblast adhesion and proliferation, Carbohydr. Polym. 108 (2014) 91-98.

[69] L. Cui, J. Jia, Y. Guo, Y. Liu, P. Zhu, Preparation and characterization of IPN hydrogels composed of chitosan and gelatin cross-linked by genipin, Carbohydr. Polym. 99 (2014) 31-38.

[70] S. Gorgieva, V. Kokol, Preparation, characterization, and in vitro enzymatic degradation of chitosan-gelatine hydrogel scaffolds as potential biomaterials, J. Biomed. Mater. Res. A 100 (2012) 1655-1667.

[71] M.L. Duarte, M.C. Ferreira, M.R. Marvão, J. Rocha, An optimised method to determine the degree of acetylation of chitin and chitosan by FTIR spectroscopy, Int. J. Biol. Macromol. 31 (2002) 1-8.

[72] U. Manna, S. Bharani, S. Patil, Layer-by-layer self-assembly of modified hyaluronic acid/chitosan based on hydrogen bonding. Biomacromol 10 (2009) 2632-2639.

[73] S. Hong, K. Yang, B. Kang, C. Lee, I.T. Song, E. Byun, K.I. Park, S.-W. Cho, H. Lee, Hyaluronic acid catechol: a biopolymer exhibiting a pH-dependent adhesive or cohesive property for human neural stem cell engineering, Adv. Funct. Mater. 23 (2013) 1774-1780.

[74] Z. Hong, G.M. Luz, P.J. Hampel, M. Jin, A. Liu, X. Chen, J.F. Mano, Mono-dispersed bioactive glass nanospheres: preparation and effects on biomechanics of mammalian cells, J. Biomed. Mater. Res. A 95 (2010) 747-754.

[75] Y.-F. Goh, A.Z. Alshemary, M. Akram, M.R. Abdul Kadir, R. Hussain, Bioactive glass: an in-vitro comparative study of doping with nanoscale copper and silver particles, Int. J. Appl. Glas. Sci. 5 (2014) 255-266.

[76] T. Nardo, V. Chiono, G. Ciardelli, M. Tabrizian, PolyDOPA mussel-inspired coating as a means for hydroxyapatite entrapment on polytetrafluoroethylene surface for application in periodontal diseases, Macromol. Biosci. 16 (2015) 288-298.

[77] S.B. Lee, Y.M. Lee, K.W. Song, M.H. Park, Preparation and properties of polyelectrolyte complex sponges composed of hyaluronic acid and chitosan and their biological behaviors, J. Appl. Polym. Sci. 90 (2003) 925-932.

[78] M.N. Rodrigues, M.B. Oliveira, R.R. Costa, J.F. Mano, Chitosan/chondroitin sulfate membranes produced by polyelectrolyte complexation for cartilage engineering, Biomacromol 17 (2016) 2178-2188.

[79] L. Ninan, J. Monahan, R.L. Stroshine, J.J. Wilker, R. Shi, Adhesive strength of marine mussel extracts on porcine skin, Biomater 24 (2003) 4091-4099.

[80] F. Scognamiglio, A. Travan, M. Borgogna, I. Donati, E. Marsich, J.W.A.M. Bosmans, L. Perge, M.P. Foulc, N.D. Bouvy, S. Paoletti, Enhanced bioadhesivity of dopaminefunctionalized polysaccharidic membranes for general surgery applications, Acta Biomater. 44 (2016) 232-242.

[81] A. Travan, F. Scognamiglio, M. Borgogna, E. Marsich, I. Donati, L. Tarusha, M. Grassi, S. Paoletti, Hyaluronan delivery by polymer demixing in polysaccharide-based hydrogels and membranes for biomedical applications, Carbohydr. Polym. 150 (2016) 408-418

[82] J. Mota, N. Yu, S.G. Caridade, G.M. Luz, M.E. Gomes, R.L. Reis, J.A. Jansen, X.F. Walboomers, J.F. Mano, Chitosan/bioactive glass nanoparticle composite membranes for periodontal regeneration, Acta Biomater. 8 (2012) 4173-4180.
[83] D. Wang, J. Zhang, Y. Zhong, M. Chu, W. Chang, Z. Yao, Mussel-inspired biocompatible free-standing adhesive films assembled layer-by-layer with waterresistance, RSC Adv. 8 (2018) 18904-18912.

[84] M.C. Bottino, M.V. Jose, V. Thomas, D.R. Dean, G.M. Janowski, Freeze-dried acellular dermal matrix graft: effects of rehydration on physical, chemical, and mechanical properties, Dent. Mater. 25 (2009) 1109-1115.

[85] M. Coïc, V. Placet, E. Jacquet, C. Meyer, Propriétés mécaniques des membranes de collagène, Rev. Stomatol. Chir. Maxillofac. 111 (2010) 286-290.

[86] T.D. Gomes, S.G. Caridade, M.P. Sousa, S. Azevedo, M.Y. Kandur, E.T. Öner, N.M Alves, J.F. Mano, Adhesive free-standing multilayer films containing sulfated levan for biomedical applications, Acta Biomater. 69 (2018) 183-195.

[87] M.C. Bottino, V. Thomas, G. Schmidt, Y.K. Vohra, T.-M.G. Chu, M.J. Kowolik, G.M. Janowski, Recent advances in the development of GTR/GBR membranes for periodontal regeneration-a materials perspective, Dent. Mater. 28 (2012) 703-721.

[88] A.I. Neto, N.L. Vasconcelos, S.M. Oliveira, D. Ruiz-Molina, J.F. Mano, Highthroughput topographic, mechanical, and biological screening of multilayer films containing mussel-inspired biopolymers, Adv. Funct. Mater. 26 (2016) 2745-2755.

[89] J.R. Burkett, J.L. Wojtas, J.L. Cloud, J.J. Wilker, A method for measuring the adhesion strength of marine mussels, J. Adhes. 85 (2009) 601-615.

[90] E. Nejati, V. Firouzdor, M.B. Eslaminejad, F. Bagheri, Needle-like nano hydroxyapatite/poly(l-lactide acid) composite scaffold for bone tissue engineering application, Mater. Sci. Eng. C 29 (2009) 942-949.

[91] Y.L. Cui, A.D. Qi, W.G. Liu, X.H. Wang, H. Wang, D.M. Ma, K.D. Yao, Biomimetic surface modification of poly(l-lactic acid) with chitosan and its effects on articular chondrocytes in vitro, Biomater 24 (2003) 3859-3868.

[92] S.I. Roohani-Esfahani, S. Nouri-Khorasani, Z.F. Lu, R.C. Appleyard, H. Zreiqat, Effects of bioactive glass nanoparticles on the mechanical and biological behavior of composite coated scaffolds, Acta Biomater. 7 (2011) 1307-1318.

[93] S.J. Kim, S.R. Shin, K.B. Lee, Y.D. Park, S.I. Kim, Synthesis and characteristics of polyelectrolyte complexes composed of chitosan and hyaluronic acid, J. Appl. Polym. Sci. 91 (2004) 2908-2913.

[94] M.J. Cardoso, S.G. Caridade, R.R. Costa, J.F. Mano, Enzymatic degradation of polysaccharide-based layer-by-layer structures, Biomacromol 17 (2016) 1347-1357.

[95] M. Bellantone, H.D. Williams, L.L. Hench, Broad-spectrum bactericidal activity of Ag20-doped bioactive glass, Antimicrob. Agents Chemother. 46 (2002) 1940-1945.

[96] T.N. Kim, Q.L. Feng, J.O. Kim, J. Wu, H. Wang, G.C. Chen, F.Z. Cui, Antimicrobial effects of metal ions $(\mathrm{Ag}+, \mathrm{Cu} 2+, \mathrm{Zn} 2+)$ in hydroxyapatite, J. Mater. Sci. Mater. Med. 9 (1998) 129-134.

[97] X. Chatzistavrou, J.C. Fenno, D. Faulk, S. Badylak, T. Kasuga, A.R. Boccaccini, P. Papagerakis, Fabrication and characterization of bioactive and antibacterial composites for dental applications, Acta Biomater. 10 (2014) 3723-3732.

[98] J. Wang, Z. Li, Y. Liang, S. Zhu, Z. Cui, H. Bao, Y. Liu, X. Yang, Cytotoxicity and antibacterial efficacy of silver nanoparticles deposited onto dopamine-functionalised titanium, Mater. Exp. 5 (2015) 191-200.

[99] S.P. Valappil, J.C. Knowles, M. Wilson, Effect of silver-doped phosphate-based glasses on bacterial biofilm growth, Appl. Environ. Microbiol. 74 (2008) 5228-5230.

[100] M. Bellantone, N.J. Coleman, L.L. Hench, Bacteriostatic action of a novel fourcomponent bioactive glass, J. Biomed. Mater. Res. 51 (2000) 484-490.

[101] K. Mijnendonckx, N. Leys, J. Mahillon, S. Silver, R. Van Houdt, Antimicrobial silver: uses, toxicity and potential for resistance, Biometals 26 (2013) 609-621.

102] Z.-M. Xiu, J. Ma, P.J.J. Alvarez, Differential effect of common ligands and molecula oxygen on antimicrobial activity of silver nanoparticles versus silver ions, Environmental Science \& Technology 45 (20) (2011) 9003-9008.

[103] A. Hilonga, J.-K. Kim, P.B. Sarawade, D.V. Quang, G. Shao, G. Elineema, H.T. Kim, Silver-doped silica powder with antibacterial properties, Powder Technol. 215216 (2012) 219-222.

[104] F.E. Ciraldo, L. Liverani, L. Gritsch, W.H. Goldmann, A.R. Boccaccini, Synthesis and characterization of silver-doped mesoporous bioactive glass and its applications in conjunction with electrospinning, Materials 11 (2018) 692. 